\title{
Evidence for strong lateral seismic velocity variation in the lower crust and upper mantle beneath the California margin
}

\author{
Voon Hui Lai ${ }^{1}$, Robert W. Graves ${ }^{2}$, Shengji Wei ${ }^{3}$ and Don Helmberger ${ }^{1}$
}

Regional seismograms from earthquakes in Northern California show a systematic difference in arrival times across Southern California where long period (30 - 50 seconds) SH waves arrive up to 15 seconds earlier at stations near the coast compared with sites towards the east at similar epicentral distances. We attribute this time difference to heterogeneity of the velocity structure at the crust - mantle interface beneath the California margin. To model these observations, we propose a fast seismic layer, with thickness growing westward from the San Andreas along with a thicker and slower continental crust to the east. Synthetics generated from such a model are able to match the observed timing of $\mathrm{SH}$ waveforms better than existing 3D models. The presence of a strong upper mantle buttressed against a weaker crust has a major influence in how the boundary between the Pacific plate and North American plate deforms and may explain the observed asymmetric strain rate across the boundary. 
30 Keywords (6 max):

31 Waveform modeling, lithosphere, California, plate boundary, velocity structure, San Andreas

32 fault 


\section{Introduction}

The lithospheric structure beneath the California margin plays an important role in controlling how the plate boundary between Pacific plate and North American plate deforms.

37 Geodetic studies (Chery, 2008; Schmalzle et al., 2006; Wdowinski et al., 2007) have shown an asymmetry in strain accumulation across the San Andreas Fault (SAF). The asymmetry is

39 attributed to factors including laterally heterogeneous elastic properties in the upper crust $(0-20$

$40 \mathrm{~km}$ ) and varying elastic lithospheric thickness across the fault in the lower crust. Here, we

41 present seismic observations that are consistent with the lateral transition in elastic properties

42 across the SAF boundary, involving the lower crust and upper mantle structure beneath the

43 California margin, as shown schematically in Figure 1.

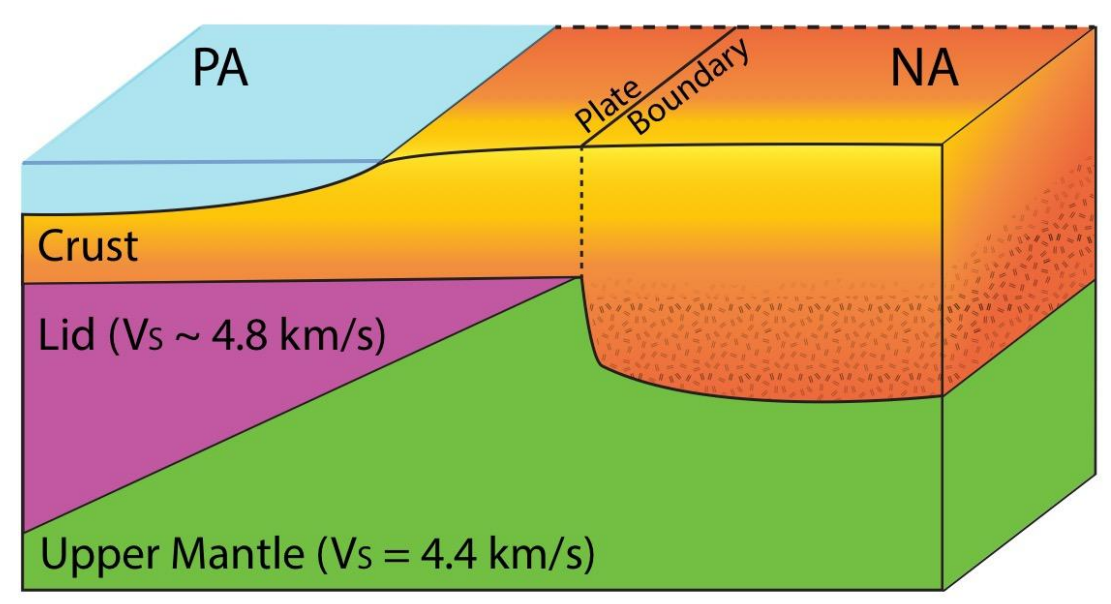

Figure 1

A schematic drawing of our proposed model. The lid (defined in text), which is faster than its surrounding medium, grows in thickness from the plate boundary towards Pacific plate (PA). In order to better fit the arrival times for inland stations (details in Section 3), the crust below the 
North American plate (NA) is modeled with a thick, relatively low-velocity crust.

The seismic lithosphere or lid, as defined in Anderson (1995) is a zone of relatively high

46 seismic velocity in the uppermost mantle, generally overlying a low velocity zone (LVZ) under

47 oceans and cratons. The lid and underlying LVZ are different from the mechanically-defined

48 lithosphere-asthenosphere boundary, although both are closely related, and the seismological

49 layers are often used to outline mechanical structure (Stein and Wysession, 2009). Pure path

50 (1D) models indicate that the Pacific plate has a thick $(\sim 60 \mathrm{~km})$ lid overlaying a strong LVZ

51 extending to below a depth of $300 \mathrm{~km}$ (Gaherty et al., 1999; Tan and Helmberger, 2007). In

52 contrast, the continental Western United States (WUS) structure is characterized by a relatively

53 slower, thinner lid $(10-20 \mathrm{~km})$ along with a weaker mantle LVZ (Grand and Helmberger,

54 1984). Despite these large lateral differences, the vertical travel times through these two

55 structures are quite similar. Thus, studies utilizing teleseismic phases with nearly vertical ray

56 paths (e.g., most global tomographic models) have difficulty resolving the lateral variation in

57 shear wave velocity structure across the plate boundary.

Using regional S-SS differential travel times, Melbourne and Helmberger (2001) showed

59 that there is lateral variation within the sub-crustal mantle characterized by the presence of a

60 seismic lid beneath California with thickness increasing from $0 \mathrm{~km}$ in Eastern California to 55

$61 \mathrm{~km}$ along the Pacific plate (see Figure S1 in Supplementary material (SM)). As the Pacific plate

62 with a thick lid has lower dextral strain compared to the North American plate with a thin lid,

63 they propose that the lid structure may modulate the deformation across the plate boundary.

64 However, the sampling sites of the lid thickness, denoted by the SS reflection points, are located 
65 along the coast of Baja California and therefore cannot precisely resolve the lid thickness

66 beneath the main California coastal region. deforms requires an accurate image of the deep structure along the plate boundary. Seismic studies since the 1970s indicate large variability in velocity structure along this boundary. For example, Zandt and Furlong (1982) combined teleseismic travel-time data and thermal models

71 to infer lithospheric-thinning along the San Andreas fault system in northern California. More

72 recently, Wang et al (2013) used surface wave tomography to map out lateral velocity variations

73 to a depth of $300 \mathrm{~km}$ throughout the southwestern United States, finding similar lithospheric

74 thinning to the east of the San Andreas fault in the Mendocino region as well as high velocity

75 regions within the upper mantle at depths up to $200 \mathrm{~km}$ that they correlate with fossil slab

76 structures. Other recent studies took advantage of the improved station density coverage to

77 retrieve regional velocity structure of the crust and uppermost mantle using seismic tomography

78 (e.g. Hauksson (2000); Prindle and Tanimoto (2006)), adjoint waveform tomography (Tape et al.

79 (2009)) or receiver function techniques (e.g. Zhu and Kanamori (2000); Yan and Clayton

80 (2007); Lekic et al. (2011); Levander and Miller (2012); Ford et al. (2014)). Many of these

81 regional velocity features are incorporated in the development of 3D velocity models by the

82 Southern California Earthquake Center (SCEC), which are discussed later.

83 Multiple earthquakes, namely the 2014/03/10 Mw 6.8, 2005/06/15 Mw 7.2, and

84 2010/01/10 M6.5 events in Mendocino region and the 2014/08/25 Mw 6.0 Napa earthquake,

85 present a unique opportunity to directly study the lateral variation in the lower crust - upper

86 mantle structure beneath the California margin using regional waveforms. The earthquakes

87 occurred in Northern California and the waveforms were recorded by the BK network operated 
88 by the Northern California Seismic Network (NCSN) and the CI network operated by the

89 Southern California Seismic Network (SCSN) at regional distances $\left(3-11^{\circ}\right)$ (Figure 2a inset).

90 The recorded waveforms exhibit significant travel time differences (discussed in Section 2),

91 suggesting possible lateral heterogeneity of the lithospheric structure beneath the California 92 margin.

3D waveform-modeling is useful to investigate anomalous behaviors in the seismic wave

94 field, but can be prohibitive when modeling at large continental scales due to high computational

95 cost. One previous known effort in continental-scale modeling is by Ji et al. (2005) which is able

96 to explain large scale Rayleigh-wave multipathing phenomenon across western North America,

97 but lacks resolution for detailed study on ocean-continent transition. Specifically modeling the

98 crustal-sensitive waves that sample the whole continental margin on a reduced regional scale

99 allows us to refine current velocity models and constrain key features across the plate boundary.

In this study, we show that the travel times of the regional SH waveforms from these

101 events cannot be well explained by existing 1D and 3D velocity models, which are poorly

102 constrained in lower crust - upper mantle structure. We propose that a fast seismic layer beneath

103 the California coast coupled with a thick, relative slow crust beneath eastern California is

104 necessary to explain the discrepancies in travel times. The lateral variation of velocity in the

105 lower crust - upper mantle region in our proposed model suggests a similar lateral variation in

106 lithospheric strength which may play a strong role in modulating long term plate deformation

107 and explain the strain rate asymmetry across the SAF. 


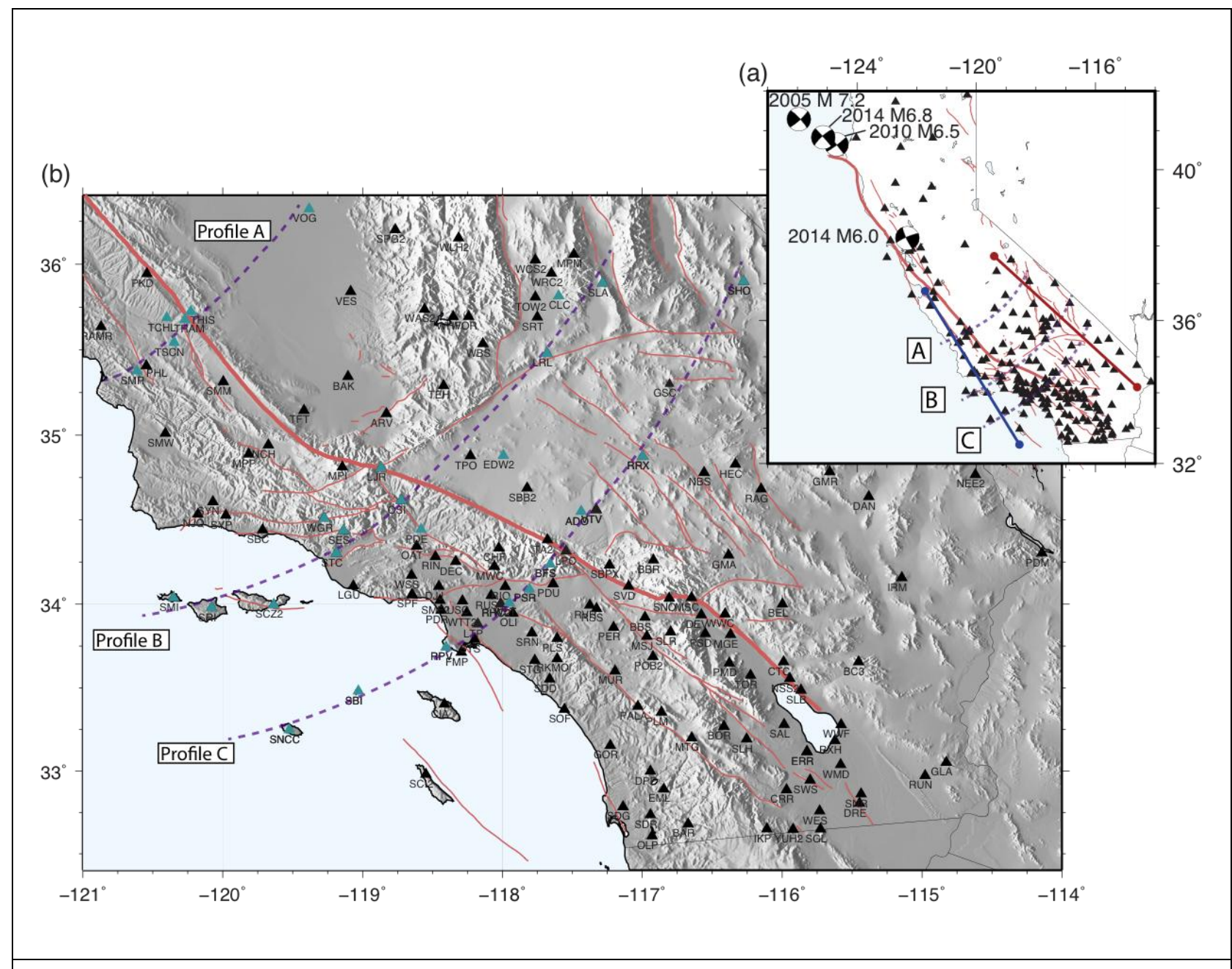

Figure 2

(a) The inset shows the location of the earthquakes in Mendocino and Napa regions (see Table 2 in SM for details), along with the distribution of broadband stations from NCSN and SCSN used in this study. The blue line displays the location of coastal stations and the red line shows the location of inland stations along radial profiles discussed later. The three azimuthal profiles (Profile A, B and C) marked in purple dashed lines are used to examine the timing and waveform variations as a function of back azimuth to the events. (b) Topographic map zoomed in on the location of SCSN stations and azimuthal profiles featured in this study. The fault map is provided by Jennings (1994) where the San Andreas Fault is highlighted in bold red line. 


\section{Observations}

The challenge in studying the ocean-continent plate boundary using regional waveforms

111 in California is that it is difficult to model the different types of waveforms (P, SH and SV)

112 simultaneously because of the limited aperture of the station distribution and the nodes in the

113 radiation patterns for strike-slip events. In this study, we concentrate on the tangential

114 component in displacement, because the stations are located close to the maxima of SH wave 115 radiation pattern for the earthquakes we analyze.

We perform cross-correlation to see how the travel times of the observed SH waveforms

117 compare with that computed from a 1-D velocity model (see Table 1 in SM) modified from the 118 layered 'Gil7' velocity model (Dreger and Romanowicz, 1994). The 1-D synthetics are 119 computed using frequency-wavenumber method by Zhu and Rivera (2002). The 'Gil7' velocity 120 model is derived from broadband waveform modeling and routinely used in moment tensor 121 inversions in Northern California. The 'Gil7' model is a relatively fast model, which has a 122 shallow Moho boundary at $25 \mathrm{~km}$ and includes a fast, mafic lower crust with a P-wave velocity $123\left(\mathrm{~V}_{\mathrm{p}}\right)$ of $6.89 \mathrm{~km} / \mathrm{s}$ and shear wave velocity $\left(\mathrm{V}_{\mathrm{s}}\right)$ of $3.98 \mathrm{~km} / \mathrm{s}$, as revealed from the San Francisco

124 Bay area seismic imaging experiment (BASIX) in 1991 (Brocher et al., 1994). The time

125 differences between the data and synthetics will show how much the 1-D velocity model deviates 126 from the true velocity structure. In this study, we use published moment tensor solutions 127 provided by the ANSS Comprehensive Earthquake Catalog (listed in Table 2 in SM). We 128 concentrate our analysis in the period range of 30 to 50 seconds. The waveforms sample up to a 129 depth of $100 \mathrm{~km}$ and are sensitive to both the lower crust and upper mantle structure (see Figure 130 S2 in SM). 
For both Mendocino and Napa earthquakes, the observed long period SH waves show a

132 systematic pattern of later arrival times (positive time delay) for sites in eastern California and

133 early arrival times (negative time delay) for sites along the coast, demonstrating that the velocity

134 structure varies laterally across California (Figure 3). The range of time shifts for the 2014

135 Mendocino event is stronger than that seen for the 2014 Napa earthquake, suggesting that the

136 waveforms from the Mendocino event are able to better sample this considerable structural

137 variation, which extends from Mendocino region to the south of Napa region along the coast.

138 Additionally, the pattern and strength of the time shifts seen for the 2014 Mendocino event are

139 consistent with that found for other events of similar magnitudes in the Mendocino Triple

140 Junction region (Figure 4). As a check, we also compute our own moment tensor solutions using

141 the cut-and-paste (CAP) inversion method (Zhao and Helmberger (1994) and Zhu and

142 Helmberger (1996)) and find that the time shift patterns are stable even with small variations in

143 focal mechanisms (see Figure S3 in SM). This emphasizes the role of lateral velocity variations

144 in controlling the arrival times as opposed to effects related to source location or mechanism. 


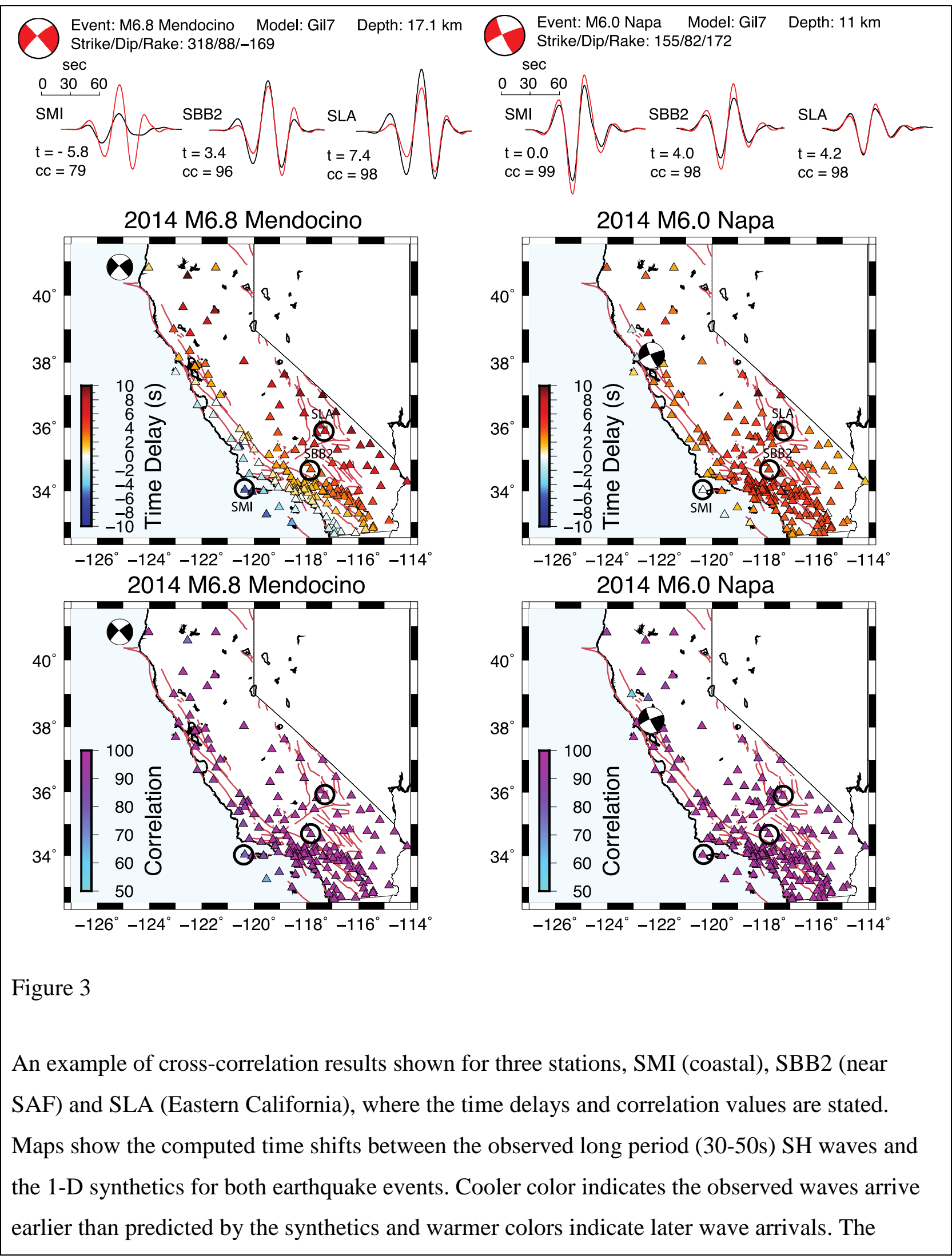


average time differences (calculated from the eastern border of California to the coast) are about $7 \mathrm{~s}$ (Napa) and $14 \mathrm{~s}$ (Mendocino) respectively. The correlation of the observations with synthetics is high, with average coefficient above 0.90 . The fit decreases for some coastal stations for the Mendocino event due to waveform interference at later arrival times but does not affect the arrival time of the first peak of the wave train.

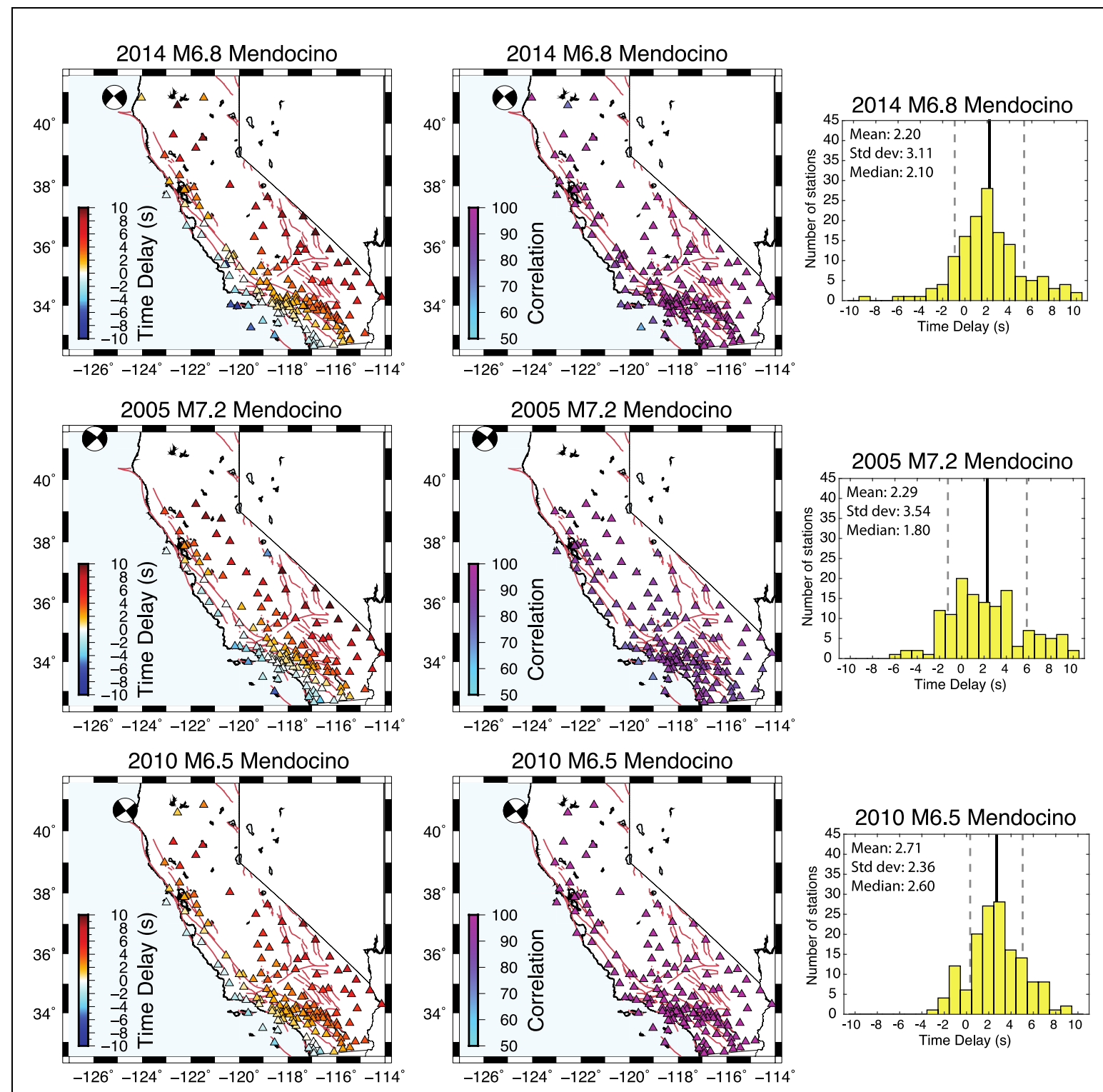

Figure 4 
Similar to Figure 3, where maps show the time delay between the observed long period SH waves and the 1-D synthetics for three events of similar magnitudes in the Mendocino region. The correlation of the observations with synthetics is high, with average coefficient above 0.90. For stations towards the coast, the observed waves arrive earlier than predicted by the 1-D synthetics, indicated by cooler colors. For stations in eastern California, the observed waves arrive later than predicted by the 1-D synthetics, indicated by warmer colors. Histograms to the right of the maps show the distribution of the time delays for each event.

Aligned waveforms from stations along the coast (blue profile line in Figure 2a) show

147 Sn-phase moveout of approximately the apparent shear wave velocity, $4.7 \mathrm{~km} / \mathrm{s}$ (Figure 5, top

148 panels). However, waveforms from inland stations, along the red profile line in Figure 2, show

149 slower Sn-phase moveout velocities less than $\sim 4.7 \mathrm{~km} / \mathrm{s}$ (Figure 5, bottom panels). As discussed

150 earlier, this feature is much stronger for the Mendocino event than for the Napa event, and it

151 suggests the presence of a shear wave velocity region along coastal California that is faster than

152 any of the structures depicted in the 'Gil7' model (see Table 1 in SM). Note that slight

153 mislocation of the epicenter and origin times only shifts the record sections, leaving the apparent

154 velocity unchanged. 

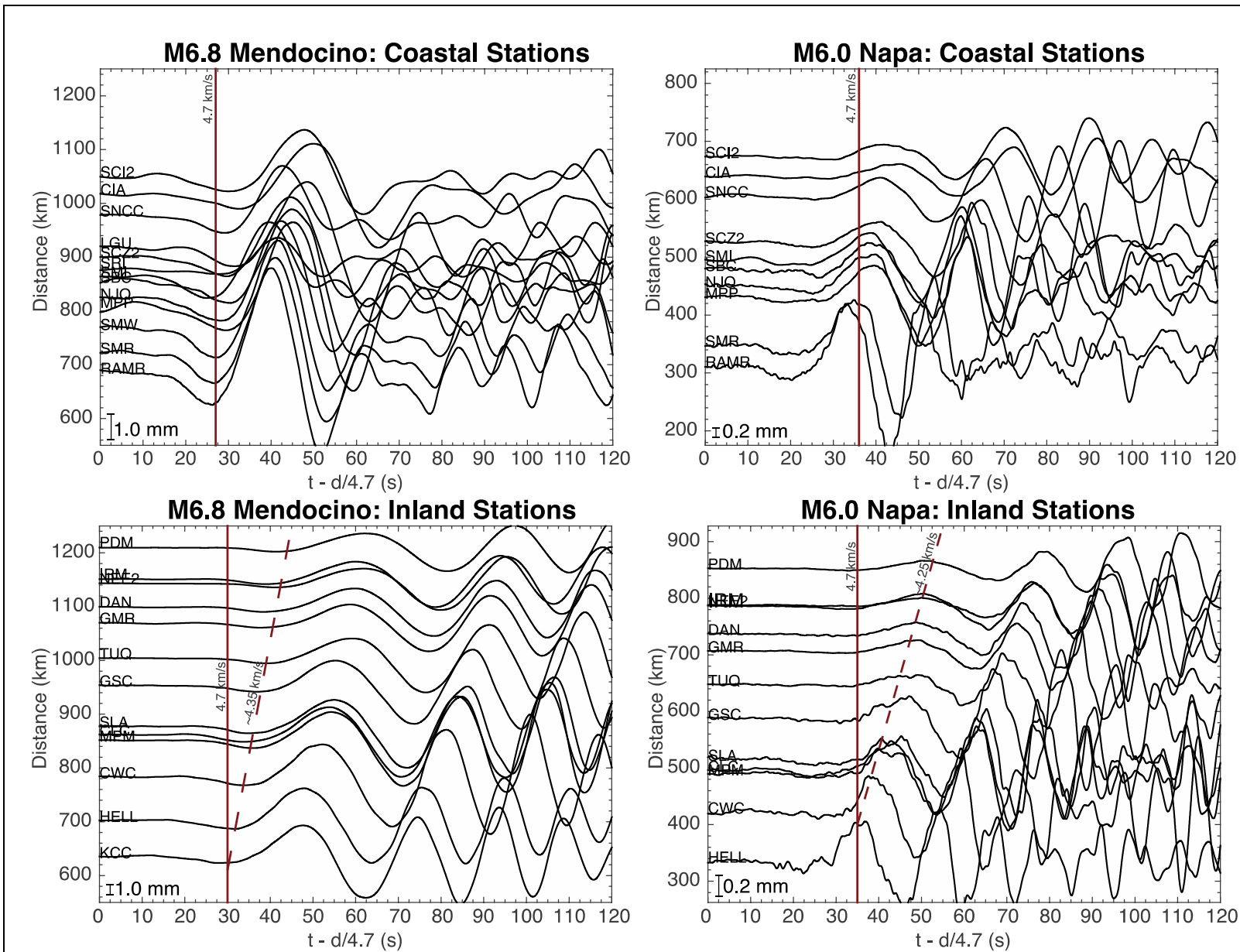

Figure 5

The record sections display broadband (1-100s) SH waveforms in displacement from the coastal stations in the top row (west of SAF; blue line in Figure 2a) and from inland stations in the bottom row (located in Eastern California; indicated by red line in Figure 2a) for both earthquake events. The arrivals of the first peak, which are the long period Sn waves, are aligned for coastal stations, showing that the waves are traveling at about the apparent shear wave velocity of $\sim 4.7$ $\mathrm{km} / \mathrm{s}$. For inland stations, there is a strong move-out of the peaks across distances indicated by the dashed lines, showing the peaks are traveling slower than the reduction velocity $(4.7 \mathrm{~km} / \mathrm{s})$. The move-out velocities are $\sim 4.35 \mathrm{~km} / \mathrm{s}$ and $\sim 4.25 \mathrm{~km} / \mathrm{s}$ for the Mendocino and Napa events, respectively.

Similarly, we observe in the azimuthal record sections (Figure 6), which span across a

156 few hundred kilometers, that the Sn waves arrive systematically earlier for coastal and offshore 
157 stations relative to the inland sites. In addition, while the arrivals following the direct $\mathrm{Sn}$ at the

158 inland stations show large amplitude coherent wave trains, the later arrivals at the coastal stations

159 become less coherent and their amplitudes are significantly decreased. The transition in

160 waveform character described above occurs near the SAF on the northernmost profile (Profile A,

161 see Figure 2 for location), and then shifts to west of the SAF further south (Profiles B and C).

162 The difference in travel times suggest that there is a strong east - west lateral variation in

163 the lower crust - upper mantle velocity structure beneath California, where the structure beneath

164 the coastal and offshore stations has a substantially faster shear wave velocity compared to that

165 beneath the inland stations. The variation in velocity structure appears independent of distance,

166 since all three profiles display similar patterns in travel time shift. The heterogeneity in structure

167 may also contribute to the distortion of later arriving waves as seen in the coastal stations. 

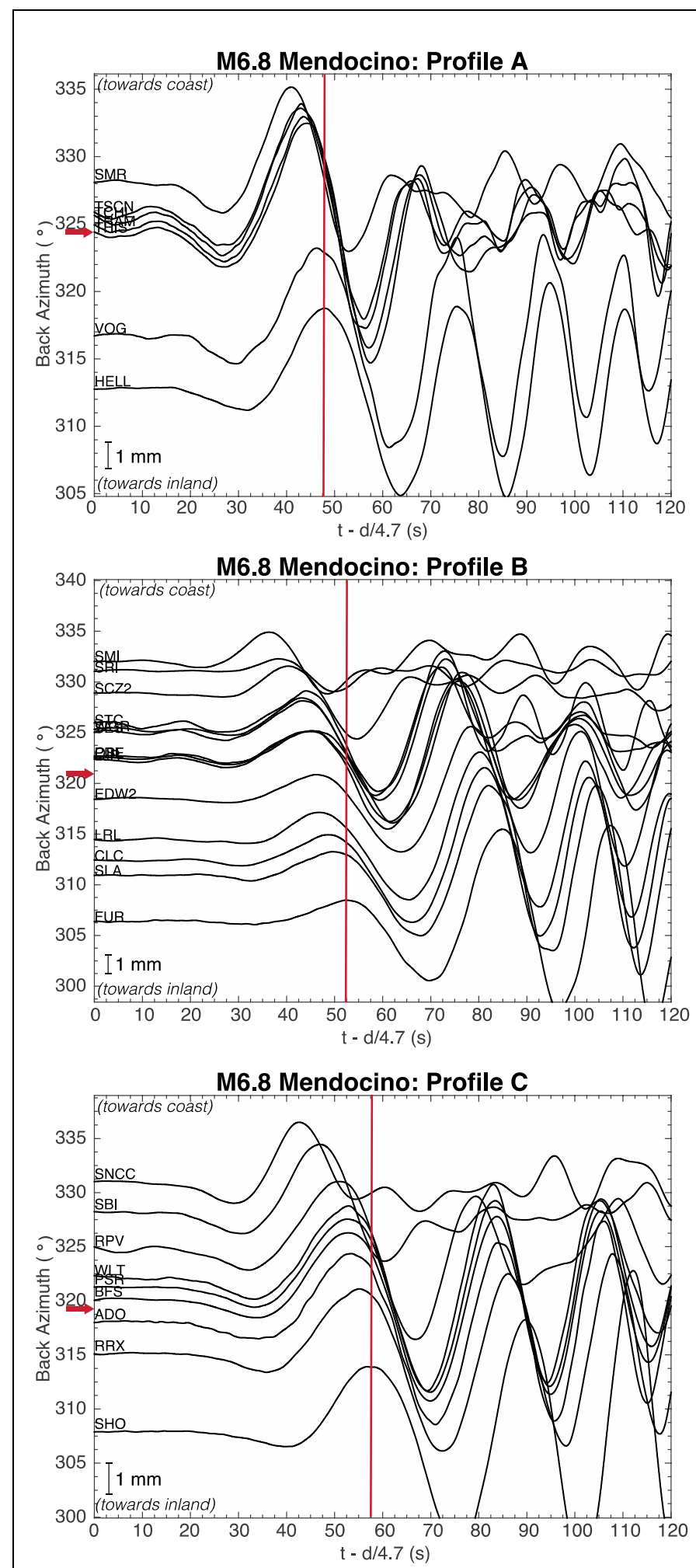

Figure 6 
Figure shows azimuthal record sections of the broadband SH waves from the 2014 Mendocino event, with time plotted using a reduction velocity of $4.7 \mathrm{~km} / \mathrm{s}$. The station locations and profile lines are shown in Figure 2. The back azimuth increases as the station location shifts from inland towards the coast. The red line acts as a guide to show the SH waves arrive earlier for stations towards the coast. The location of SAF with respect to the stations is indicated by the red arrow in each record section.

\section{Modeling}

We propose that the systematic, east-west variation in arrival times of the SH waves is

171 due to the variation in the velocity structure in the lower crust - upper mantle along the plate

172 boundary. There are several scenarios that can contribute to the variation, such as different

173 crustal thicknesses, presence of fast seismic lid, and/or different velocity in the lower crust -

174 upper mantle structure. A recent study by Tape et al. (2012) shows that the Moho depth varies

175 from $20 \mathrm{~km}$ offshore to $35 \mathrm{~km}$ inland across Southern California (along profile C in Figure 2).

176 However, the difference in arrival times cannot be solely from variation in crustal thickness. A

177 quick calculation from synthetics generated from 1-D velocity models shows that for every

178 increase in crustal thickness of $10 \mathrm{~km}$, the arrival times are delayed by 2.5 seconds (see Figure

179 S4 in SM). A 14 second time difference (calculated from the east California to the coast) would

180 suggest a $56 \mathrm{~km}$ difference in crustal thickness across California, which far exceeds the expected 181 crustal thickness in this region.

182 Thus, we propose that the early arrival times at the coastal stations are predominantly due 183 to the presence of a seismic lid west of the SAF and parallel to the coast, as presented 
184 schematically in Figure 1. In short, this seismic lid shares the same properties as the one

185 observed within the Pacific plate, with a preferred SH velocity of $4.78 \mathrm{~km} / \mathrm{s}$ (Tan and

186 Helmberger, 2007). The presence of the lid is consistent with the observed apparent velocities of

187 the long period Sn waveforms recorded by stations along the coast. As the seismic lid is much

188 faster than the upper mantle $\left(\mathrm{V}_{\mathrm{s}}\right.$ of $4.8 \mathrm{~km} / \mathrm{s}$ compared to $\left.4.4 \mathrm{~km} / \mathrm{s}\right)$, it has significant impact in

189 shortening the travel times. The velocity contrast across California was previously observed in a

190 3-D tomographic study by Hauksson (2000), where he determined a high $\mathrm{V}_{\mathrm{p}}(8.2 \mathrm{~km} / \mathrm{s})$ structure

191 at a depth around $20 \mathrm{~km}$ beneath the Southern California coastline. The structure is inferred to

192 have a $V_{p} / V_{s}$ ratio of 1.77 , which translates to a $V_{s}$ of $4.6 \mathrm{~km} / \mathrm{s}$, slightly lower than our estimated

193 SH velocity of the lid. This difference can possibly be explained by seismic anisotropy in the

194 oceanic plate where Tan and Helmberger (2007) found SH velocity to be about 5\% faster than

195 SV velocity. The gradual decrease in travel times with back azimuth suggests that the lid may

196 grow in thickness from inland towards the coast. The lid thickness is less well constrained

197 compared to the crustal thickness, and can be as thick as $60 \mathrm{~km}$, as suggested by Tan and

198 Helmberger (2007).

To explain the delayed arrival times for inland stations, we propose the velocity structure

200 beneath stations east of the SAF is significantly slower than to the west. This is consistent with

201 previous studies that have found eastern California is characterized by a relatively thick crust

202 (Zhu and Kanamori, 2000) comprised of relative low seismic velocities especially within the

203 lower crust beneath the Mojave block (Ammon and Zandt, 1993; Helmberger et al., 2001). 
uniform trending northwest-to-southeast as indicated in Figure 7. The boundary, where the lid

208

209

210

211 grows in thickness, tracks the stations with zero time shifts (from Figure 3 and Figure 4) and runs mostly parallel with SAF in Northern California, and shifts to the west by $100 \mathrm{~km}$ after the 'Big Bend' in Southern California. The lower crustal velocity at $3.7 \mathrm{~km} / \mathrm{s}$ in Eastern California is compatible with regional modeling of Basin and Range events (Song et al., 1996).

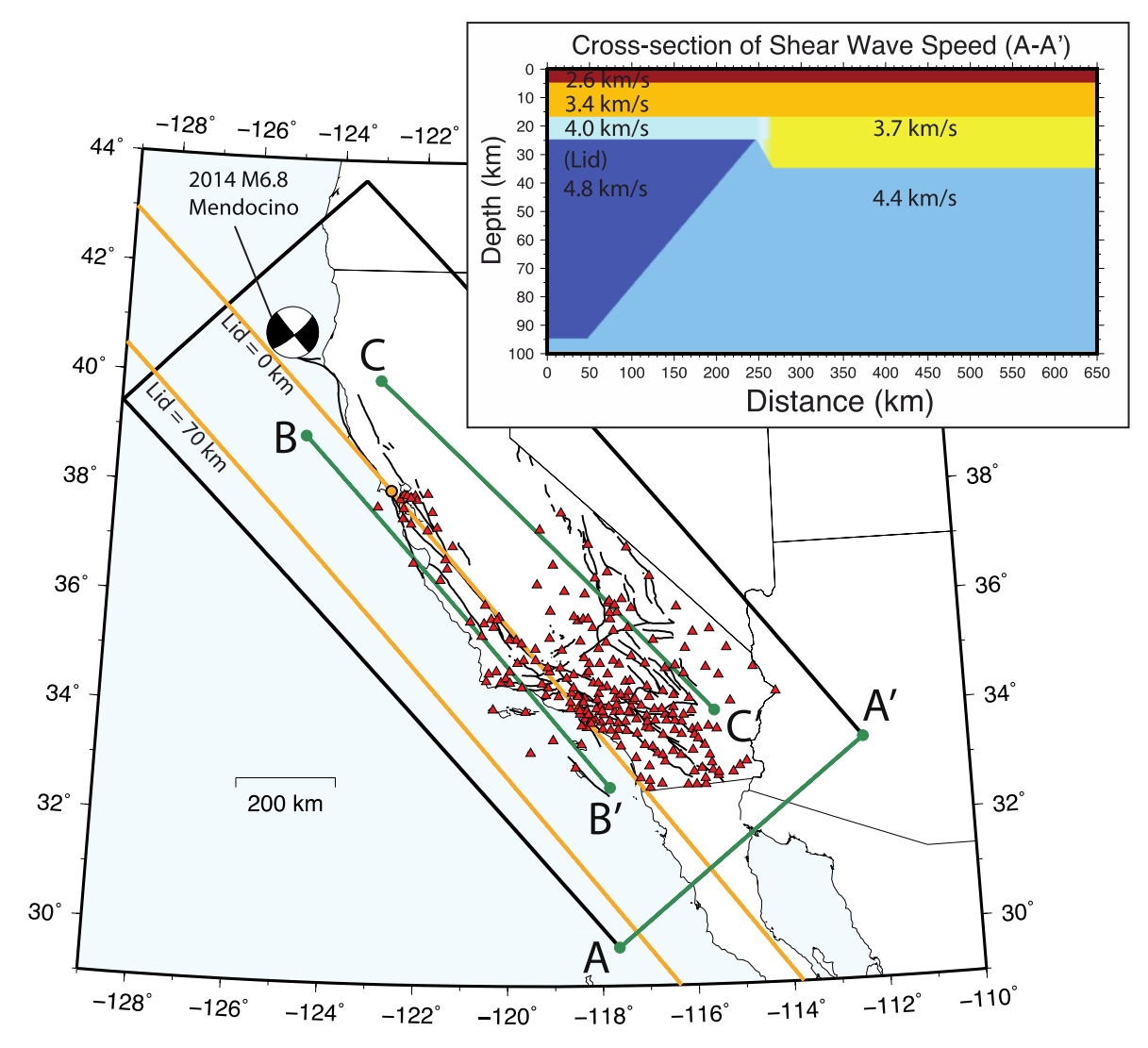

Figure 7

Map illustrates the configuration used in the 3-D finite difference modeling. Black box marks the surface boundary of the 3-D grid. The cross section profile (A - A') shows the 2-D shear wave velocity structure, which is a modification of the 1-D 'Gil7' model (see Table 1 in SM) with the lid structure, the thicker crust on the east and an additional low velocity zone. Yellow parallel lines delineate the zone where the lid thickness increases from 0 to $70 \mathrm{~km}$. The event modelled is 
the 2014 M 6.8 Mendocino earthquake. Profile B-B' and Profile C-C' are shown in Figure 10.

To test our hypothesis, we use the 3-D finite difference method (Graves, 1996) to

213 generate synthetics from our proposed model. The model is discretized with a uniform spacing of

$214 \quad 0.5 \mathrm{~km}$. We consider a 2-step approach to test the effects of the main features in our proposed

215 structure, which are the fast lid on the west, and the low velocity thicker crust on the east. We

216 first model the synthetics using a velocity model that only includes the fast lid, which improves

217 the fit of the SH arrival times between the synthetics and data for the coastal and offshore

218 stations, but does not affect the inland stations (Figure 8b). We then use the model that includes

219 both the fast lid and the low velocity thicker crust, and this significantly improves the fit for most

220 inland stations (Figure 8c). However, this model also decreases the fit for stations in the

221 southernmost portion of California, particularly those in the Salton Trough and Imperial Valley

222 region. It is widely known that this region has a relatively thin crust (e.g. Hauksson (2000) and

223 Tape et al. (2012)), which is clearly inconsistent with our proposed "thick crust" model. This

224 indicates that additional 3D complexities beyond that currently included in our simplified

225 representation are required to more fully explain all of the observations. The structural

226 complexities in this southernmost portion of the model should also be considered when

227 performing similar analysis of the reverse profile (south to north) using earthquakes occurring in

228 the Baja California region such as the 2010 M7.2 El Mayor-Cucapah event. Incorporating these

229 modifications is the subject of future work. 


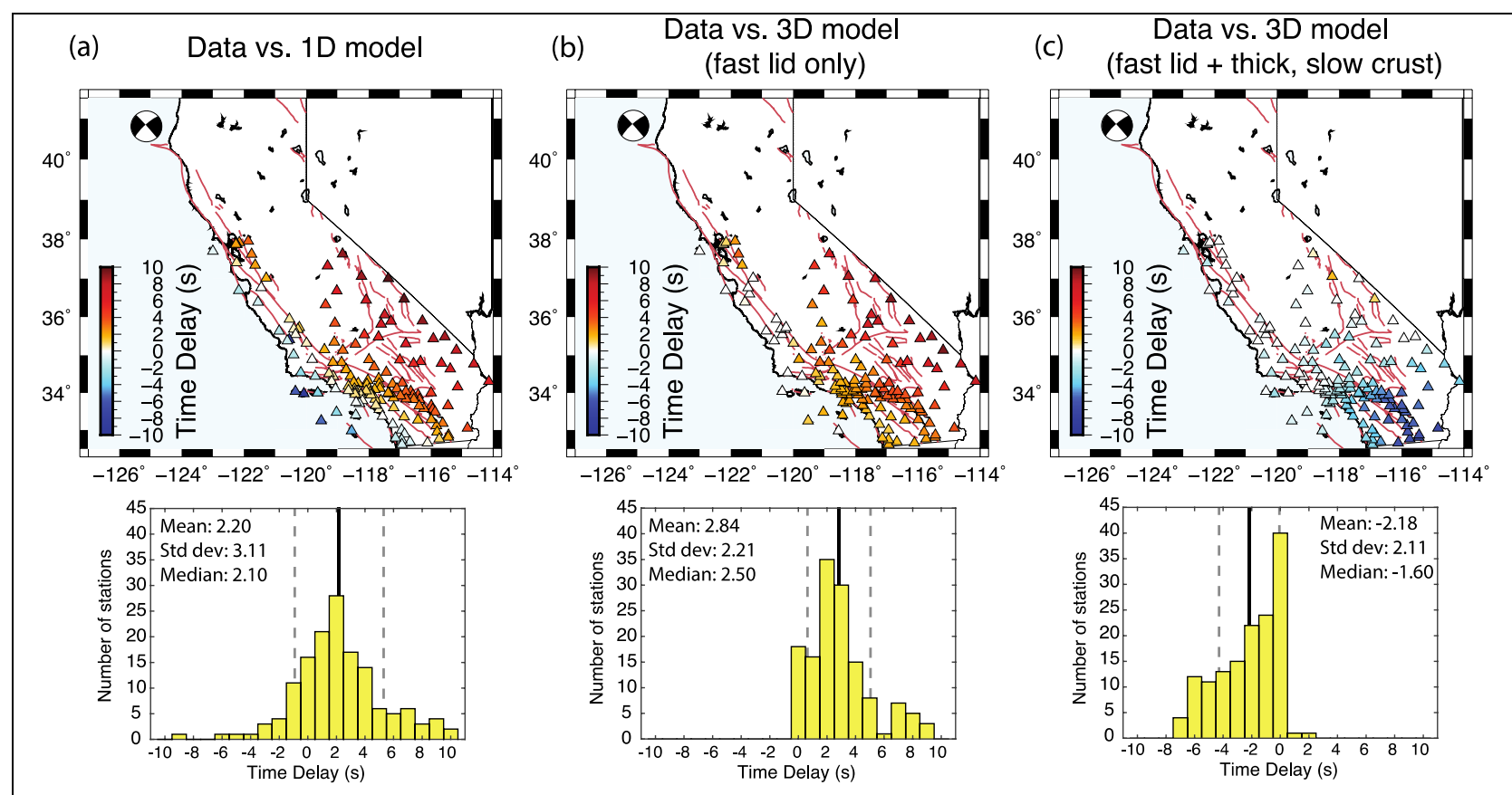

Figure 8

Maps show the time delay between the long period SH waves from the 2014 Mendocino event, and (a) the 1-D synthetics from 'Gil 7' model (same as Figure 3,4), (b) the 3-D synthetics from our proposed model with the lid only (no thick crust on the east), and (c) model with inclusion of both the lid and thicker, slower crust on the east. The histogram of the time shifts for each model comparison are shown below the map. Cooler color indicates the recorded seismograms arrive earlier than the synthetics.

We further compare our model with the present 3D velocity models available through the

232 SCEC community (Figure 9). There are three regional velocity models in total: the USGS Bay

233 Area model v08.3.0 for Northern California (Aagaard et al., 2010) and two southern California

234 Community Velocity Models (CVM), which are CVM-S4.26 (Lee et al., 2014) and CVM-

235 Harvard 15.1.0 (Shaw et al., 2015). The main advantage of the existing 3D velocity models is

236 that they have high resolution on basin and upper crust structure and those structures are well- 
237 resolved. The lower crust - upper mantle structure in the 3D models are derived from seismic

238 tomography and teleseismic surface wave data, and they generally have a poorer resolution,

239 compared to the upper crust. To construct a state-wide velocity model for comparison, we utilize

240 the SCEC Unified Community Velocity Model (UCVM 15.10.0) software framework

241 (http://scec.usc.edu/scecpedia/UCVM). This software package allows the combination of the

242 USGS Bay Area model with either of the southern California CVMs. The UCVM package also

243 prescribes a generic 1D velocity model (Hadley and Kanamori, 1977) for regions not described

244 by the $3 \mathrm{D}$ velocity models. The boundary for each of the $3 \mathrm{D}$ velocity models is shown in Figure

245 S5 in SM. The slight discontinuities at the boundaries where the different velocity models are

246 combined have no significant impact as the waveforms used in subsequent analysis are filtered at

247 long period $(30-50$ seconds).

For the coastal region, our model generally compares well with the UCVM 3D models.

249 Our model shares some key characteristics with these 3D models as illustrated in the shear wave

250 velocity cross-sections shown in Figure 10. These include: 1 ) the relatively thin crust (average 15

$251 \mathrm{~km}$ ) under the coastal region, which is evident in the northern region covered by the USGS Bay

252 Area model, and 2) the presence of fast seismic velocities (up to $\mathrm{V}_{\mathrm{S}}=5.0 \mathrm{~km} / \mathrm{s}$ ) below the Moho

253 in the southern region, particularly for CVM-S4.26, and to a lesser extent for CVM-H.

For the inland region, both sets of UCVM 3D model synthetics are too fast compared to

255 the data, which is primarily due to the fast $(4.0 \mathrm{~km} / \mathrm{s})$ structure in the USGS Bay Area model in

256 the lower crust. Hence, our model emphasizes the need for a slower structure beneath Eastern

257 California compared with these models. On the other hand, the UCVM 3D model including

258 CVM-H does well at matching the time delays near Imperial Valley, suggesting this model is

259 adequately capturing the thinning of the crust in this region. The azimuthal record sections for all 
the models are shown in Figure S6 in SM. These profiles further highlight the timing differences

261 among the models, and in particular demonstrate that the UCVM 3D models predict arrivals at

262 the inland sites that are up to 15 seconds earlier than the observations. We also note that the

263 UCVM 3D models have better fits for the amplitude of the later arrivals in the Love wave train,

264 indicating these models have a better-resolved shallow crustal structure than our simplified

265 model.

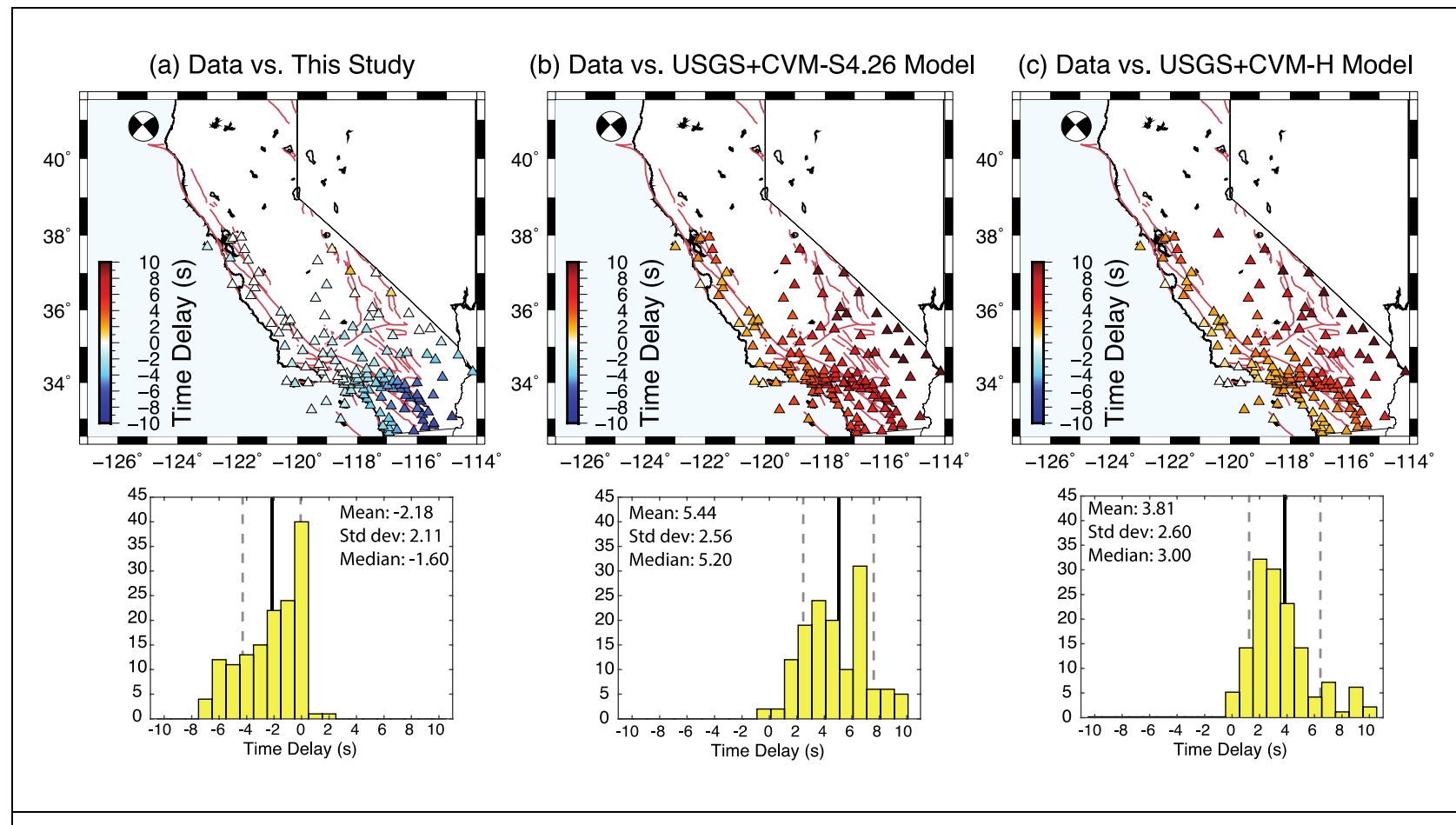

Figure 9

Maps show the time delay between the recorded long period SH waves from the 2014 Mendocino event, and the synthetics from (a) our preferred model, (b) USGS Bay Area and CVM-S4.26 Southern California model and (c) USGS Bay Area and CVM-Harvard Southern California model. Cooler color indicates the recorded seismograms arrive earlier than the synthetics. Histograms below the map show the distribution of the time delays for each model comparison. 
(a) Cross-section profile of Vs along the coast ( B - B')

(b) Cross-section profile of Vs for inland region ( C - C')

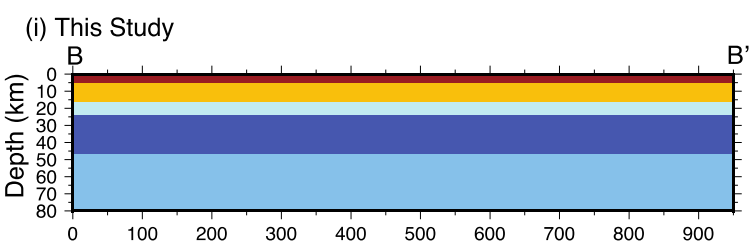

(i) This Study

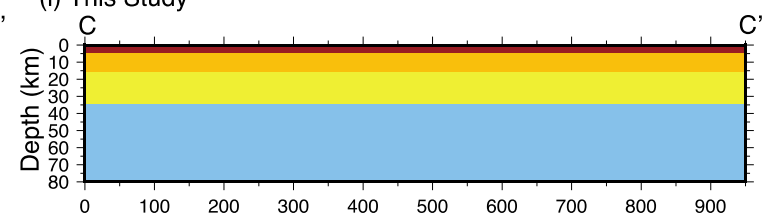

(ii) USGS Bay Area + CVM-S4.26 Model
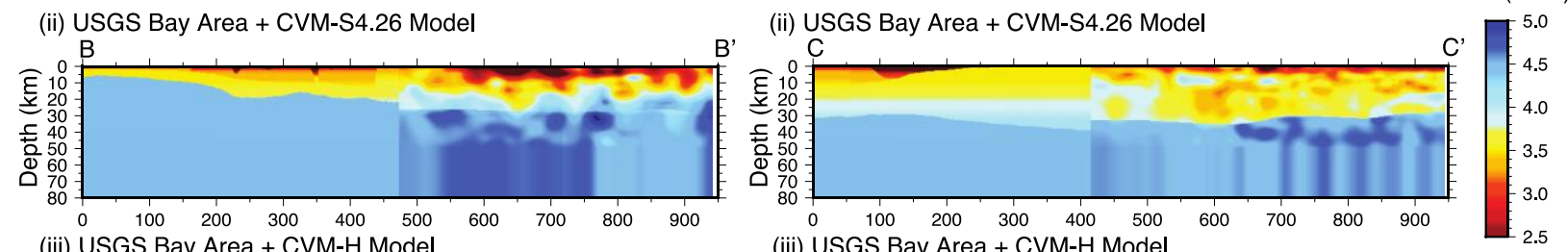

(iii) USGS Bay Area + CVM-H Model

(iii) USGS Bay Area + CVM-H Model

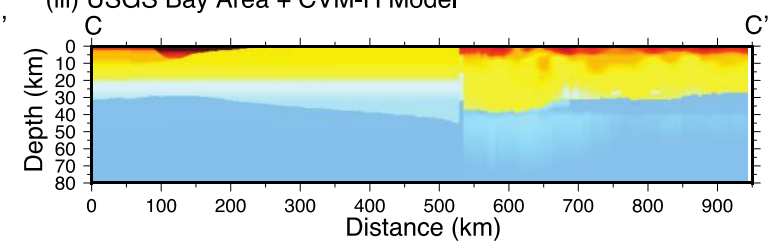

Figure 10

Cross-section profiles of shear wave (Vs) structure along Profile B - B' (coast) and Profile C C' (inland) for three 3D velocity models. The profile locations are indicated in Figure 7.

\section{Discussion and Conclusion}

The simple seismic velocity model we have developed in the present work only includes

269 lateral variations in one horizontal dimension, and is thus insufficient to capture the full 3D

270 complexity of the velocity structure in California, as illustrated in Figure 8c. In any case, even

271 though our model is simple, it does provide direct evidence for a key characteristic of the lower

272 crust - upper mantle structure beneath, which is the strong west-east lateral seismic velocity

273 contrast across the plate boundary.

Our work suggests that the fast seismic lid feature extends beyond Baja California as

275 initially proposed by Melbourne and Helmberger (2001) and is, in fact, a continuous feature 
276 parallel to the SAF along the California coastline. The waveforms recorded from the Mendocino

277 events propagate south and sample the lower crust - upper mantle structure along the entire

278 region. In addition, the travel time move-out in the observed waveforms is significantly more

279 pronounced for the Mendocino event compared to the Napa event. The Mendocino event

280 originated $80 \mathrm{~km}$ offshore, and hence the waveforms sample more of the oceanic lid along the

281 coast. The propagation path of the waveforms from the Napa event, which originated inland, are

282 mostly restricted to inland paths, away from the coastline and therefore the move-out effect due

283 to the lid is less evident.

The absolute thickness of the lid is not well constrained, as the thickness trades off with the lid velocity. However, the general behavior of the lid growing in thickness holds as we see in

286 Figure 3 and Figure 4, there is a gradual increase in travel time difference for the waveforms as 287 the ray paths shift westward. In order to the fit the observations, the lid has to be significantly 288 faster (i.e. $\left.V_{\mathrm{S}}=4.8 \mathrm{~km} / \mathrm{s}\right)$ than the velocity of upper mantle $(\mathrm{Vs}=4.4-4.5 \mathrm{~km} / \mathrm{s})$ in reference 289 models. The high shear wave velocity of the lid suggests a highly mafic composition, consistent 290 with the composition for Pacific oceanic lithosphere (Tan and Helmberger, 2007). The currently 291 available 3D velocity models for California do not adequately capture the travel-time variations 292 seen in these regional waveform data. This suggests that these data could be used as constraints 293 in future updates of these 3D models. The observed strong lateral variation in the upper mantle structure beneath California 295 likely contributes to the strain rate asymmetry and should play a significant role in modulating 296 plate deformation. Assuming the seismic velocity as a proxy for lithospheric strength, the lid 297 beneath the Pacific plate, with higher velocity, is thus much stronger than its surroundings and 298 lends strength to the Pacific plate. The shear wave velocity of the lid $(\mathrm{Vs}=4.8 \mathrm{~km} / \mathrm{s})$ is 
299 significantly higher than its surrounding medium: the lower crust has a maximum Vs of about $3004.0 \mathrm{~km} / \mathrm{s}$ and the upper mantle averages Vs of about $4.4 \mathrm{~km} / \mathrm{s}$. On the other hand, the relatively

301 lower velocity of the deep crust and absence of a strong lid beneath the North American plate

302 suggests weaker lithospheric strength. Thus, the upper mantle of the Pacific Plate should deform 303 more rigidly and differs from the North American Plate, which is in the plastic flow regime 304 (Kohlstedt et al., 1995).

Schmalzle et al. (2006) showed a scenario on how variation in effective elastic thickness (EET) can explain the strain rate asymmetry across the San Andreas fault in the Carrizo Plain region in central California. Their best fitting result requires a $38 \mathrm{~km}$ EET west of SAF and an average of $12 \mathrm{~km}$ EET east of SAF. Taking the interseismic strain rate to be inversely

309 proportional to the effective elastic thickness (EET) of the lithospheric plate, Chery (2008)

310 further showed that the interseismic strain rate profiles across northern, central and southernmost

311 California are best modeled with a thin EET along the plate boundary and thick EET on the

312 Pacific plate and Sierra Nevada province. The change in EET across the plate boundary follows

313 closely along the SAF trace in northern and central California, and moves $\sim 75 \mathrm{~km}$ westward

314 towards Elsinore Fault in southernmost California (see Figure S7 in SM). Similarly, from 315 geodetic data inversion for slip rates on faults in California, Platt and Becker (2010) proposed

316 that (1) the present velocity field reflects long-term plate motion and (2) the real lithospheric

317 transform boundary does not necessarily follow the surface trace of SAF, but rather it is a zone

318 up to $80 \mathrm{~km}$ wide, notably centered west of the SAF in southern California, and has a trend

319 straighter and closer to the plate motion vector than the SAF. 
322 of the plate boundary. A similar idea of lateral contrast in lithospheric properties is proposed in

323 Ford et al. (2014) through a Sp receiver function study as they observe a change in character of

324 lithosphere-asthenosphere boundary across the plate boundary. In addition, the transform

325 boundary in our simple model, marked by the growth of the lid structure, roughly follows along

326 the local strike of SAF except in Southern California when it moves westward by $\sim 100 \mathrm{~km}$,

327 which is in agreement with the position of the transform boundary proposed by Platt and Becker

328 (2010). The transform boundary may be characterized as the juxtaposition of the strong Pacific

329 plate due to the seismic lid, with the weak, ductile North American plate, where the lower crust -

330 upper mantle structure beneath the Californian margin controls the strain rate observed in

331 California. This plate boundary structure becomes even more complex in the southernmost

332 portion of southern California (Imperial Valley) where the crust is quite thin due to the

333 northward impingement of the East Pacific Rise into the North American plate. To more fully

334 explore the consistency of our model with the strain-rate asymmetry and long-term plate

335 deformation in California, additional quantitative analyses are needed which is beyond the scope

336 of the current work.

The velocity contrast in our model bears resemblance to the slab window formed due to

338 the migration of Mendocino Triple Junction during the evolution of the plate boundary (Furlong

339 and Schwartz, 2004). Based on our model, the lithospheric thinning, inferred by Zandt and

340 Furlong (1982) and Wang et al. (2013), may have been a prominent state-wide phenomenon

341 along the east side of the plate boundary at the lower crust - upper mantle depth range. Our

342 model focuses at much shallower depth compared to models from seismic tomography (up to

$343300 \mathrm{~km}$ in Wang et al. (2013)) hence it is less meaningful in terms of understanding past

344 subduction processes or imaging fossil slabs. Nonetheless, our model, constructed from direct 
345 seismic observation, can provide useful constraints in the development of the next generation

346 state-wide velocity models and informing the regional plate tectonic history.

This study illustrates the potential of using regional waveforms to investigate the laterally

348 varying seismic velocity structure of the lower crust - upper mantle beneath California. Our

349 simplified model, i.e. a fast seismic lid underlying the Pacific plate abutting against a thick crust

350 with relatively low seismic velocities comprising the continental North American plate, does

351 well at reproducing the systematic travel time variations of long period Sn waves observed

352 across central and southern California for events in the Mendocino region. The strong

353 heterogeneity in velocity suggests similar heterogeneity in lithospheric strength, which may

354 modulate the plate deformation in this region.

\section{Acknowledgement}

357 This work is supported by USGS Earthquake Hazards Program award G15AP00029 along with

358 partial support from NSF-Earthscope program, EAR-1358646 and USGS Cooperative

359 Agreement G14AC00109. Constructive reviews provided by Brad Aagaard, Annemarie Baltay,

360 Carl Tape and an anonymous reviewer were very helpful in improving the manuscript.

361 Waveform data for this study were accessed through the Northern California Earthquake Data

362 Center (NCEDC), doi: 10.7932/NCEDC, and Southern California Earthquake Data Center

363 (SCEDC) at Caltech, doi: 10.7909/C3WD3xH1. Maps were created using General Mapping

364 Tools (GMT) software (Wessel et al., 2013). 


\begin{tabular}{|ccccc|}
\hline Layer & Thickness $(\mathbf{k m})$ & Vs $(\mathbf{k m} / \mathbf{s})$ & Vp $\mathbf{( k m} / \mathbf{s})$ & Density $(\mathbf{g} / \mathbf{c c})$ \\
\hline \multirow{2}{*}{ Upper Crust } & 5 & 2.60 & 4.50 & 2.40 \\
& 12 & 3.40 & 6.21 & 2.68 \\
\hline Lower Crust & $8(18)$ & $3.98(3.70)$ & $6.89(6.70)$ & $3.00(2.80)$ \\
\hline (Lid) & (varies) & $(4.80)$ & $(8.30)$ & $(3.20)$ \\
\hline Upper mantle & - & 4.40 & 7.80 & 3.00 \\
\hline
\end{tabular}

\section{Table 1}

442 A description of the modified 1-D 'Gil7' model. The main modification is a simplification of the 443 crustal layer where the number of layers is reduced from 7 to 3 . The Moho depth in this model is $44425 \mathrm{~km}$. The parameters of the fast lid and the thicker, slower crust used in western and eastern 445 parts, respectively, of this study's preferred model, are listed in parentheses. 


\begin{tabular}{|c|c|c|c|c|c|c|c|c|}
\hline \multirow[t]{2}{*}{ Event Name } & \multirow{2}{*}{$\begin{array}{l}\text { Origin Time } \\
\text { (UTC) }\end{array}$} & \multirow{2}{*}{$\begin{array}{c}\text { Moment } \\
\text { Magnitude } \\
(\mathrm{Mw})\end{array}$} & \multirow[t]{2}{*}{ Latitude } & \multirow[t]{2}{*}{ Longitude } & \multirow{2}{*}{$\begin{array}{l}\text { Depth } \\
(\mathbf{k m})\end{array}$} & \multicolumn{3}{|c|}{ Focal Mechanism } \\
\hline & & & & & & Strike & Rake & Dip \\
\hline 2014 Napa & $\begin{array}{c}2014-08-24 \\
10: 20: 44.070\end{array}$ & 6.0 & 38.215 & -122.312 & 11.1 & 155 & 172 & 82 \\
\hline $\begin{array}{c}2014 \\
\text { Mendocino }\end{array}$ & $\begin{array}{c}2014-03-10 \\
05: 18: 13.430\end{array}$ & 6.8 & 40.829 & -125.134 & 16.6 & 318 & -169 & 88 \\
\hline $\begin{array}{c}2005 \\
\text { Mendocino }\end{array}$ & $\begin{array}{c}2005-06-15 \\
02: 50: 54.190\end{array}$ & 7.2 & 41.292 & -125.953 & 16.0 & 317 & 172 & 83 \\
\hline $\begin{array}{c}2010 \\
\text { Mendocino }\end{array}$ & $\begin{array}{c}2010-01-10 \\
00: 27: 39.320\end{array}$ & 6.5 & 40.652 & -124.692 & 29.3 & 233 & 0 & 85 \\
\hline
\end{tabular}

449 Table 2

450 The earthquake source parameters used in this study are provided by the ANSS Comprehensive

451 Earthquake Catalog (ComCat), which can be assessed at

452 http://earthquake.usgs.gov/earthquakes/search/. 


\section{Reference}

Aagaard, B.T., Graves, R.W., Rodgers, A., Brocher, T.M., Simpson, R.W., Dreger, D., 457 Petersson, N.A., Larsen, S.C., Ma, S., Jachens, R.C., 2010. Ground-Motion Modeling of 458 Hayward Fault Scenario Earthquakes, Part II: Simulation of Long-Period and Broadband Ground 459 Motions. Bulletin of the Seismological Society of America 100, 2945-2977.

460 Ammon, C.J., Zandt, G., 1993. Receiver Structure beneath the Southern Mojave Block, 461 California. Bulletin of the Seismological Society of America 83, 737-755.

462 Anderson, D.L., 1995. Lithosphere, Asthenosphere, and Perisphere. Reviews of Geophysics 33, 463 125-149.

464 Brocher, T.M., McCarthy, J., Hart, P.E., Holbrook, W.S., Furlong, K.P., McEvilly, T.V., Hole, 465 J.A., Klemperer, S.L., 1994. Seismic evidence for a lower-crustal detachment beneath san 466 francisco bay, california. Science 265, 1436-1439.

467 Chery, J., 2008. Geodetic strain across the San Andreas fault reflects elastic plate thickness 468 variations (rather than fault slip rate). Earth and Planetary Science Letters 269, 352-365.

469 Dreger, D., Romanowicz, B., 1994. Source characteristics of events in the San Francisco Bay 470 region. U.S. Geol. Surv. Open-File Rept 94-176, 301-309.

471 Ford, H.A., Fischer, K.M., Lekic, V., 2014. Localized shear in the deep lithosphere beneath the 472 San Andreas fault system. Geology 42, 295-298.

473 Furlong, K.P., Schwartz, S.Y., 2004. Influence of the Mendocino Triple Junction on the 474 Tectonics of Coastal California. Annual Review of Earth and Planetary Sciences 32, 403-433.

475 Gaherty, J.B., Kato, M., Jordan, T.H., 1999. Seismological structure of the upper mantle: a 476 regional comparison of seismic layering. Physics of the Earth and Planetary Interiors 110, 21-41.

477 Grand, S.P., Helmberger, D.V., 1984. Upper Mantle Shear Structure of North-America. 478 Geophysical Journal International 76, 399-438.

479 Graves, R.W., 1996. Simulating seismic wave propagation in 3D elastic media using staggered480 grid finite differences. Bulletin of the Seismological Society of America 86, 1091-1106.

481 Hadley, D., Kanamori, H., 1977. Seismic structure of the transverse ranges, California. 482 Geological Society of America Bulletin 88, 1469-1478.

483 Hauksson, E., 2000. Crustal structure and seismicity distribution adjacent to the Pacific and 484 North America plate boundary in southern California. Journal of Geophysical Research 105, 48513875. 
486

487

488

489

490

491

492

493

494

495

496

497

498

499

500

501

502

503

504

505

506

507

508

509

510

511

512

513

514

515

516

517

518

519

520

Helmberger, D.V., Song, X.J., Zhu, L., 2001. Crustal complexity from regional waveform tomography: Aftershocks of the 1992 Landers earthquake, California. Journal of Geophysical Research 106, 609.

Herrmann, R.B., 2013. Computer Programs in Seismology: An Evolving Tool for Instruction and Research. Seismological Research Letters 84, 1081-1088.

Jennings, C.W., 1994. Fault activity map of California and adjacent areas, with locations and ages of recent volcanic eruptions California Department of Conservation, Division of Mines and Geology, Geologic Data Map No. 6.

Ji, C., Tsuboi, S., Komatitsch, D., Tromp, J., 2005. Rayleigh-wave multipathing along the west coast of North America. Bulletin of the Seismological Society of America 95, 2115-2124.

Kohlstedt, D.L., Evans, B., Mackwell, S.J., 1995. Strength of the Lithosphere - Constraints Imposed by Laboratory Experiments. Journal of Geophysical Research-Solid Earth 100, 1758717602.

Lee, E.-J., Chen, P., Jordan, T.H., Maechling, P.B., Denolle, M.A.M., Beroza, G.C., 2014. Full3-D tomography for crustal structure in Southern California based on the scattering-integral and the adjoint-wavefield methods. Journal of Geophysical Research: Solid Earth 119, 6421-6451.

Lekic, V., French, S.W., Fischer, K.M., 2011. Lithospheric thinning beneath rifted regions of Southern California. Science 334, 783-787.

Levander, A., Miller, M.S., 2012. Evolutionary aspects of lithosphere discontinuity structure in the western U.S. Geochemistry, Geophysics, Geosystems 13, n/a-n/a.

Melbourne, T., Helmberger, D., 2001. Mantle control of plate boundary deformation. Geophysical Research Letters 28, 4003-4006.

Platt, J.P., Becker, T.W., 2010. Where is the real transform boundary in California? Geochemistry, Geophysics, Geosystems 11, 1525-2027.

Prindle, K., Tanimoto, T., 2006. Teleseismic surface wave study forS-wave velocity structure under an array: Southern California. Geophysical Journal International 166, 601-621.

Schmalzle, G., Dixon, T., Malservisi, R., Govers, R., 2006. Strain accumulation across the Carrizo segment of the San Andreas Fault, California: Impact of laterally varying crustal properties. Journal of Geophysical Research 111.

Shaw, J.H., Plesch, A., Tape, C., Suess, M.P., Jordan, T.H., Ely, G., Hauksson, E., Tromp, J., Tanimoto, T., Graves, R., Olsen, K., Nicholson, C., Maechling, P.J., Rivero, C., Lovely, P., Brankman, C.M., Munster, J., 2015. Unified Structural Representation of the southern California crust and upper mantle. Earth and Planetary Science Letters 415, 1-15.

Song, X.J., Helmberger, D.V., Zhao, L., 1996. Broad-band modelling of regional seismograms: The basin and range crustal structure. Geophysical Journal International 125, 15-29. 
521 Stein, S., Wysession, M., 2009. An introduction to seismology, earthquakes, and earth structure.

522 John Wiley \& Sons.

523 Tan, Y., Helmberger, D.V., 2007. Trans-Pacific upper mantle shear velocity structure. Journal of 524 Geophysical Research 112.

525 Tape, C., Liu, Q., Maggi, A., Tromp, J., 2009. Adjoint tomography of the southern California 526 crust. Science 325, 988-992.

527 Tape, C., Plesch, A., Shaw, J.H., Gilbert, H., 2012. Estimating a Continuous Moho Surface for 528 the California Unified Velocity Model. Seismological Research Letters 83, 728-735.

529 Wang, Y., Forsyth, D.W., Rau, C.J., Carriero, N., Schmandt, B., Gaherty, J.B., Savage, B., 2013. 530 Fossil slabs attached to unsubducted fragments of the Farallon plate. Proc Natl Acad Sci U S A $531 \quad 110,5342-5346$.

532 Wdowinski, S., Smith-Konter, B., Bock, Y., Sandwell, D., 2007. Diffuse interseismic 533 deformation across the Pacific-North America plate boundary. Geology 35, 311.

534 Wessel, P., Smith, W.H.F., Scharroo, R., Luis, J., Wobbe, F., 2013. Generic Mapping Tools: 535 Improved Version Released. Eos, Transactions American Geophysical Union 94, 409-410.

536 Yan, Z., Clayton, R.W., 2007. Regional mapping of the crustal structure in southern California 537 from receiver functions. Journal of Geophysical Research 112.

538 Zandt, G., Furlong, K.P., 1982. Evolution and thickness of the lithosphere beneath coastal 539 California. Geology 10, 376.

540 Zhao, L.-S., Helmberger, D.V., 1994. Source estimation from broadband regional seismograms. 541 Bulletin of the Seismological Society of America 84, 91-104.

542 Zhu, L., Helmberger, D.V., 1996. Advancement in source estimation techniques using broadband 543 regional seismograms. Bulletin of the Seismological Society of America 86, 1634-1641.

544 Zhu, L., Kanamori, H., 2000. Moho depth variation in southern California from teleseismic 545 receiver functions. Journal of Geophysical Research 105, 2969.

546 Zhu, L., Rivera, L.A., 2002. A note on the dynamic and static displacements from a point source 547 in multilayered media. Geophysical Journal International 148, 619-627. 


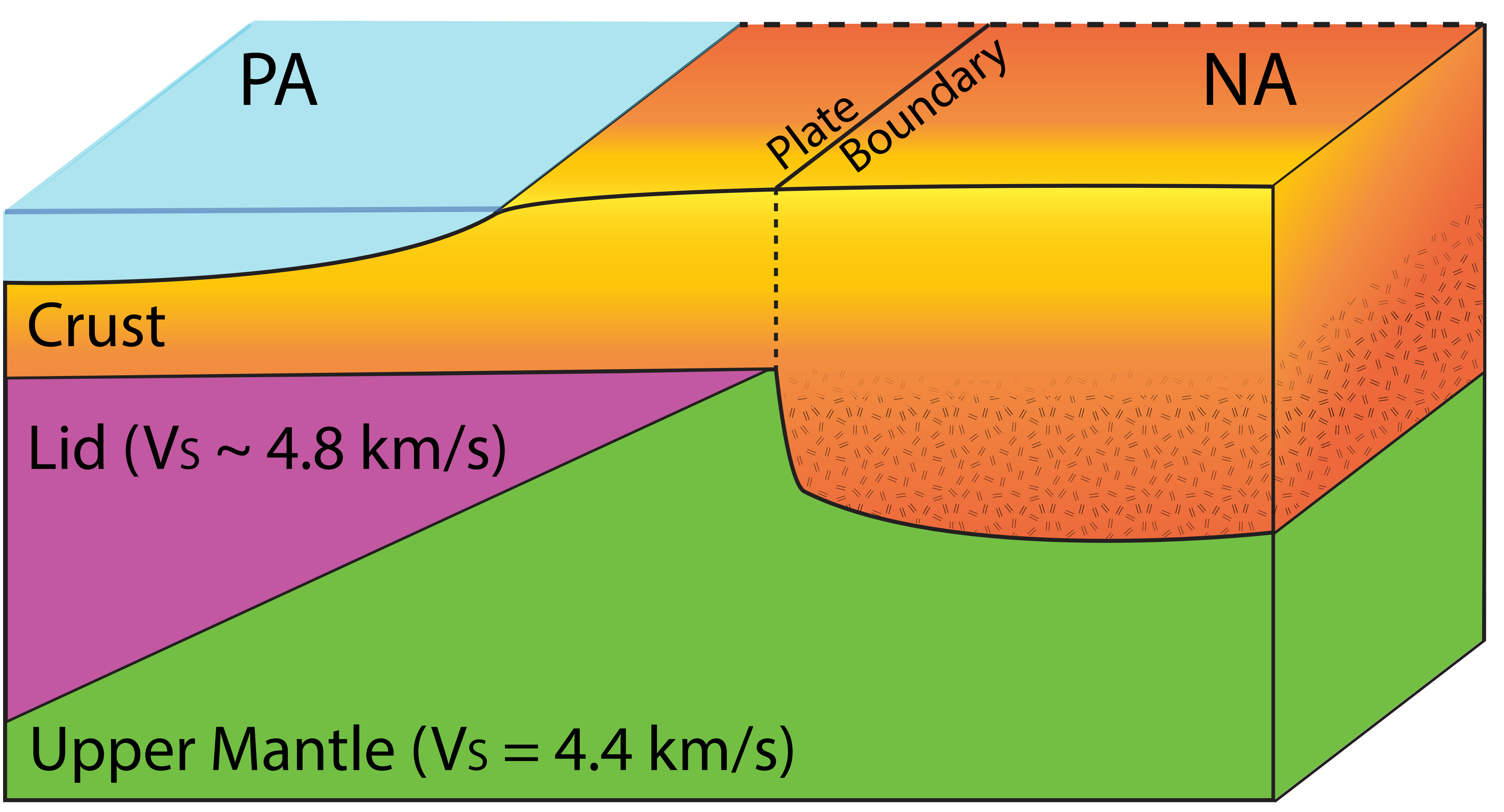

Crust

Upper Mantle $(\mathrm{Vs}=4.4 \mathrm{~km} / \mathrm{s})$ 
(b)

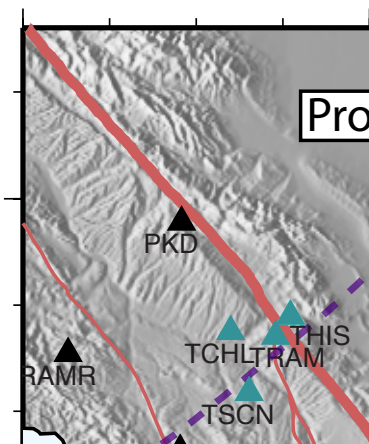

VES

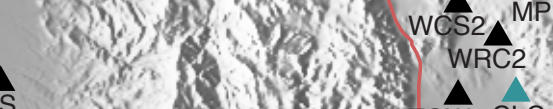

$36^{\circ}$

$5^{\circ}-$

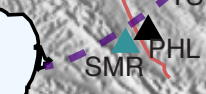
in sic on

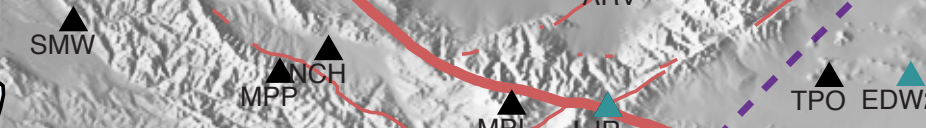
1.2. MP TR

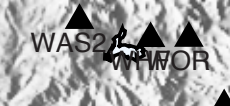
TOW $_{2} \mathrm{CLC}$ , SLA Thi He

\section{$2005 \mathrm{M}$} $2014 \mathrm{M} 6.8$

8 $2010 \mathrm{M} 6.5$

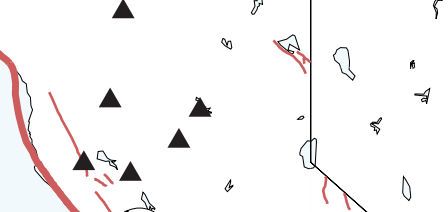

2014 M6.0

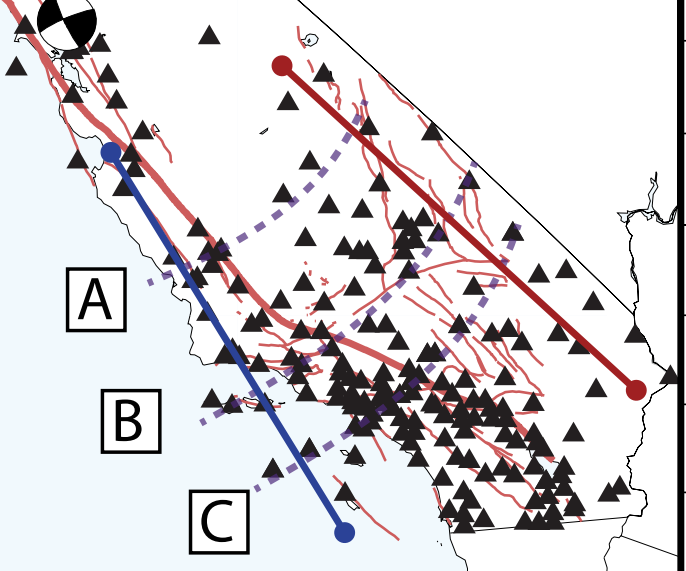

A $H E C$ ADOFV IN - Niwa' 13

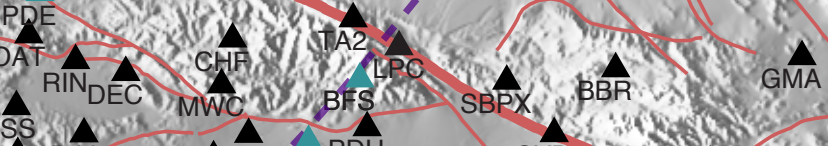

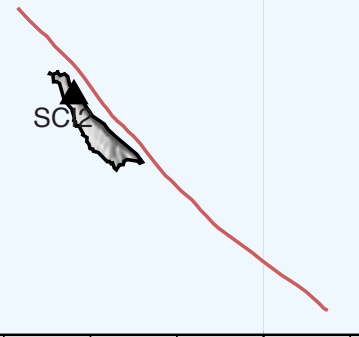




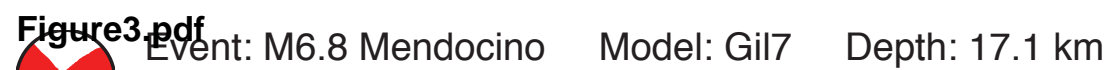
Strike/Dip/Rake: 318/88/-169 sec

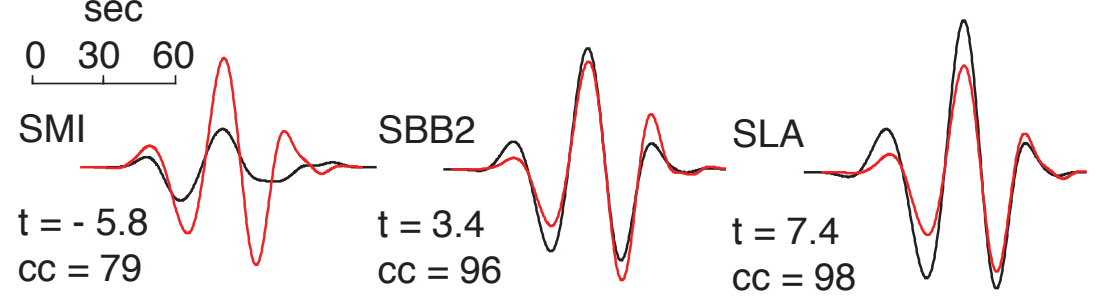

\section{M6.8 Mendocino}

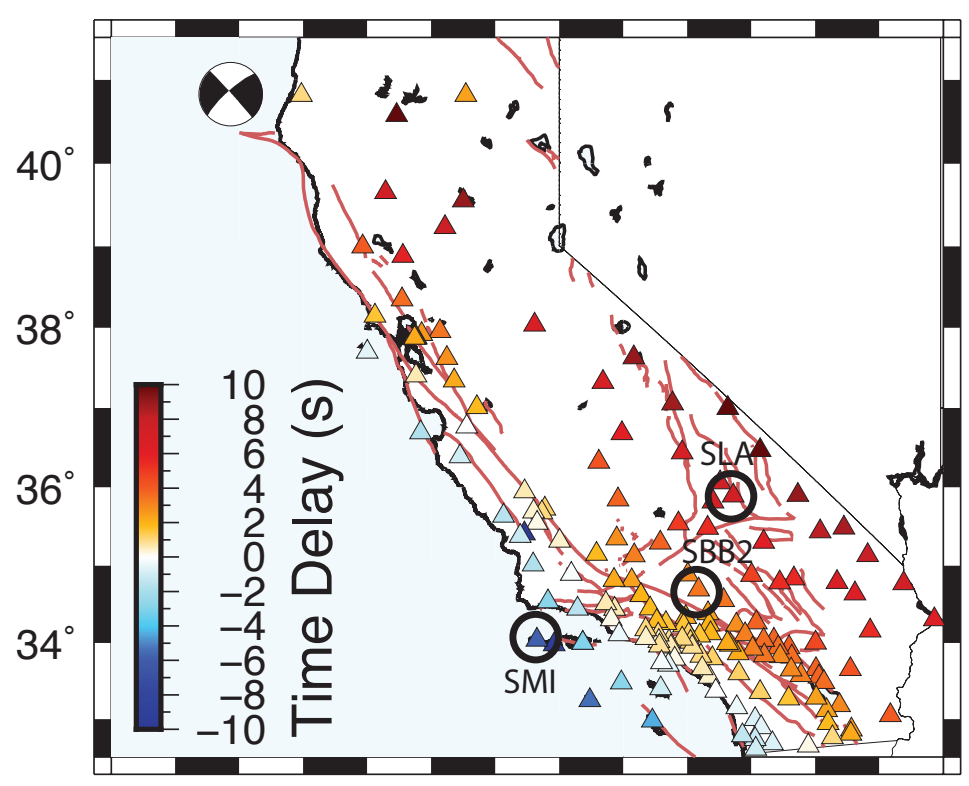

$-126^{\circ}-124^{\circ}-122^{\circ}-120^{\circ}-118^{\circ}-116^{\circ}-114^{\circ}$ 2014 M6.8 Mendocino

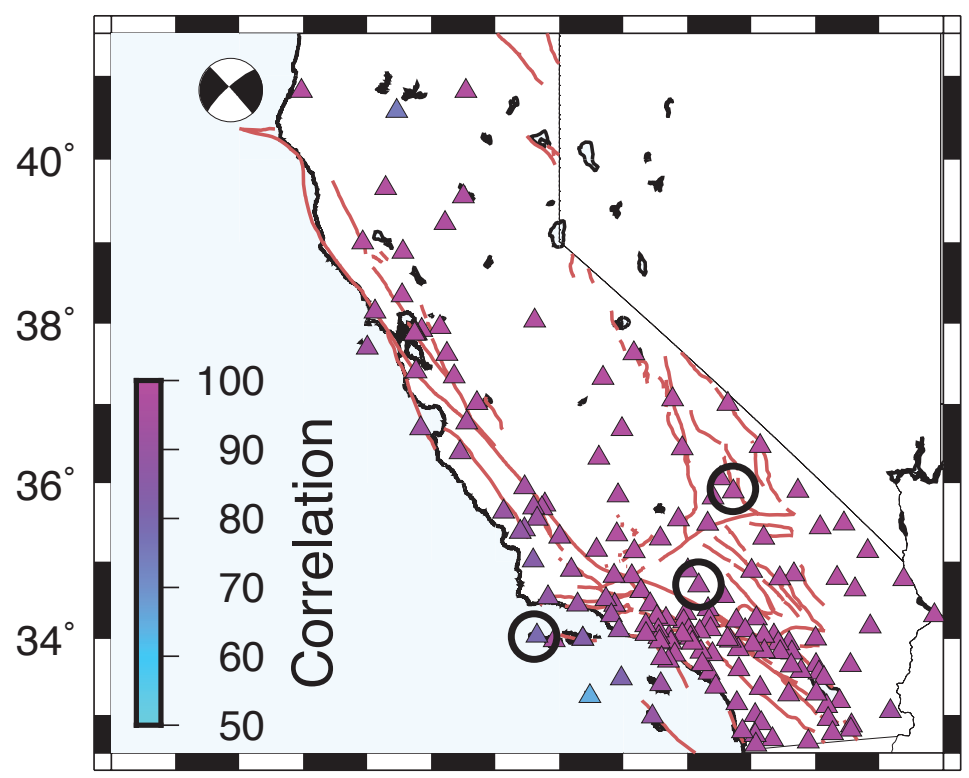

$-126^{\circ}-124^{\circ}-122^{\circ}-120^{\circ}-118^{\circ}-116^{\circ}-114^{\circ}$
Event: M6.0 Napa Model: Gil7 Depth: $11 \mathrm{~km}$ Strike/Dip/Rake: 155/82/172

sec
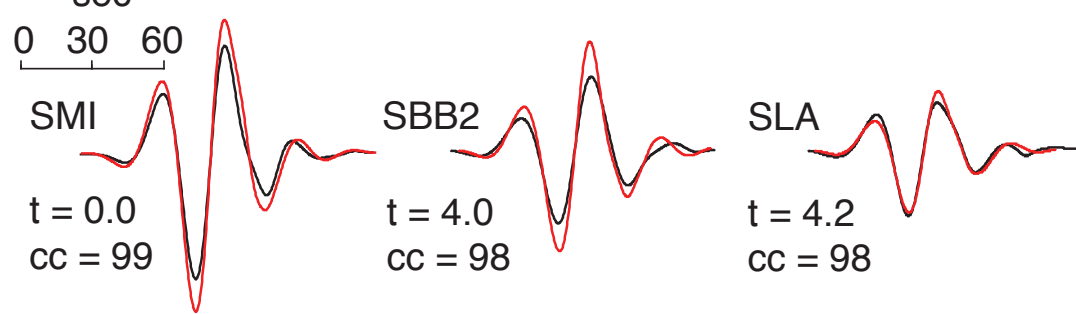

2014 M6.0 Napa

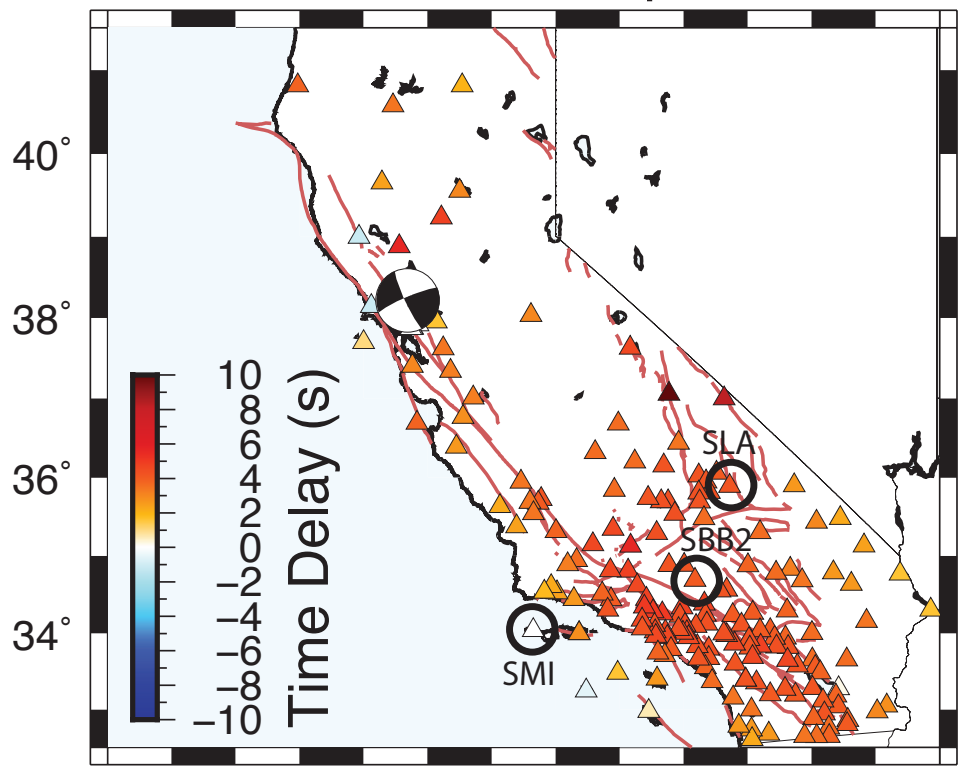

$-126^{\circ}-124^{\circ}-122^{\circ}-120^{\circ}-118^{\circ}-116^{\circ}-114^{\circ}$ 2014 M6.0 Napa

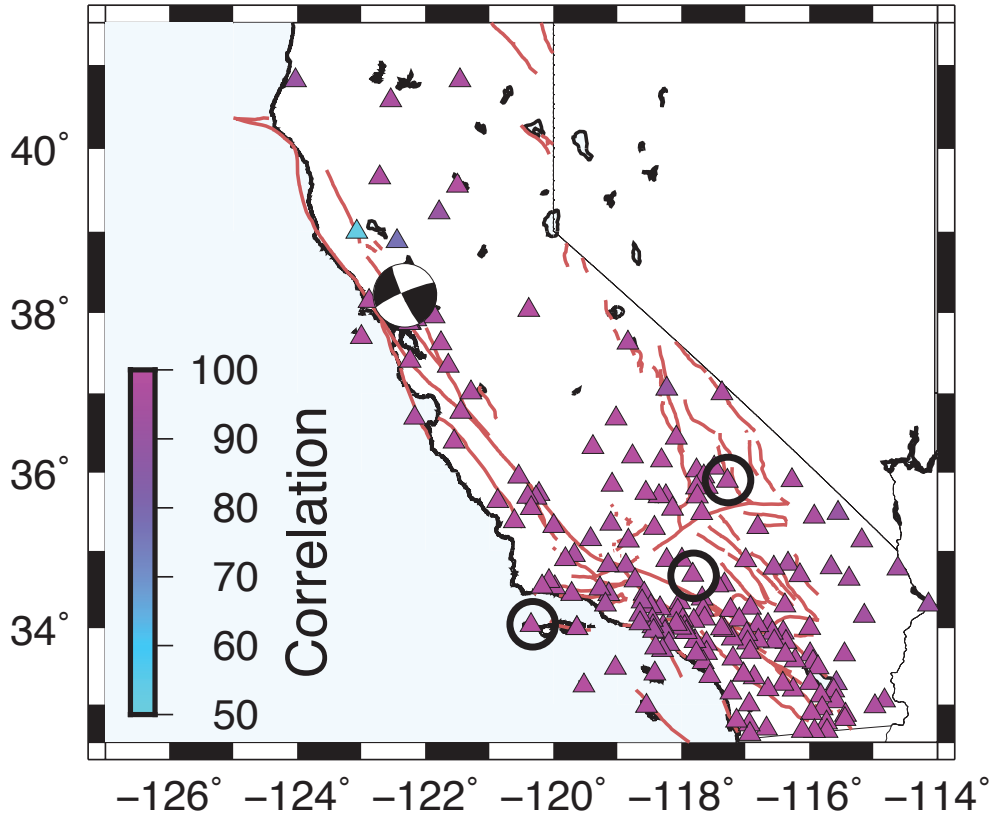




\section{Figure4.pdf 2014 M6.8 Mendocino}
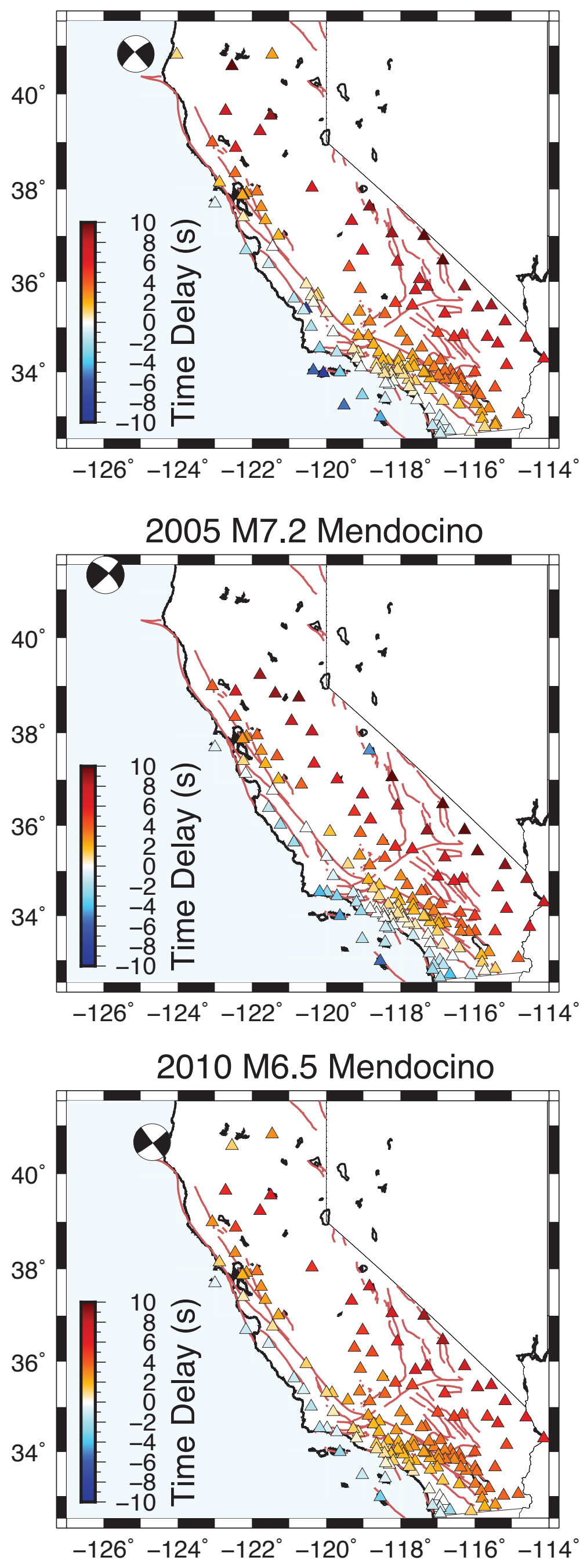

\section{M6.8 Mendocino}
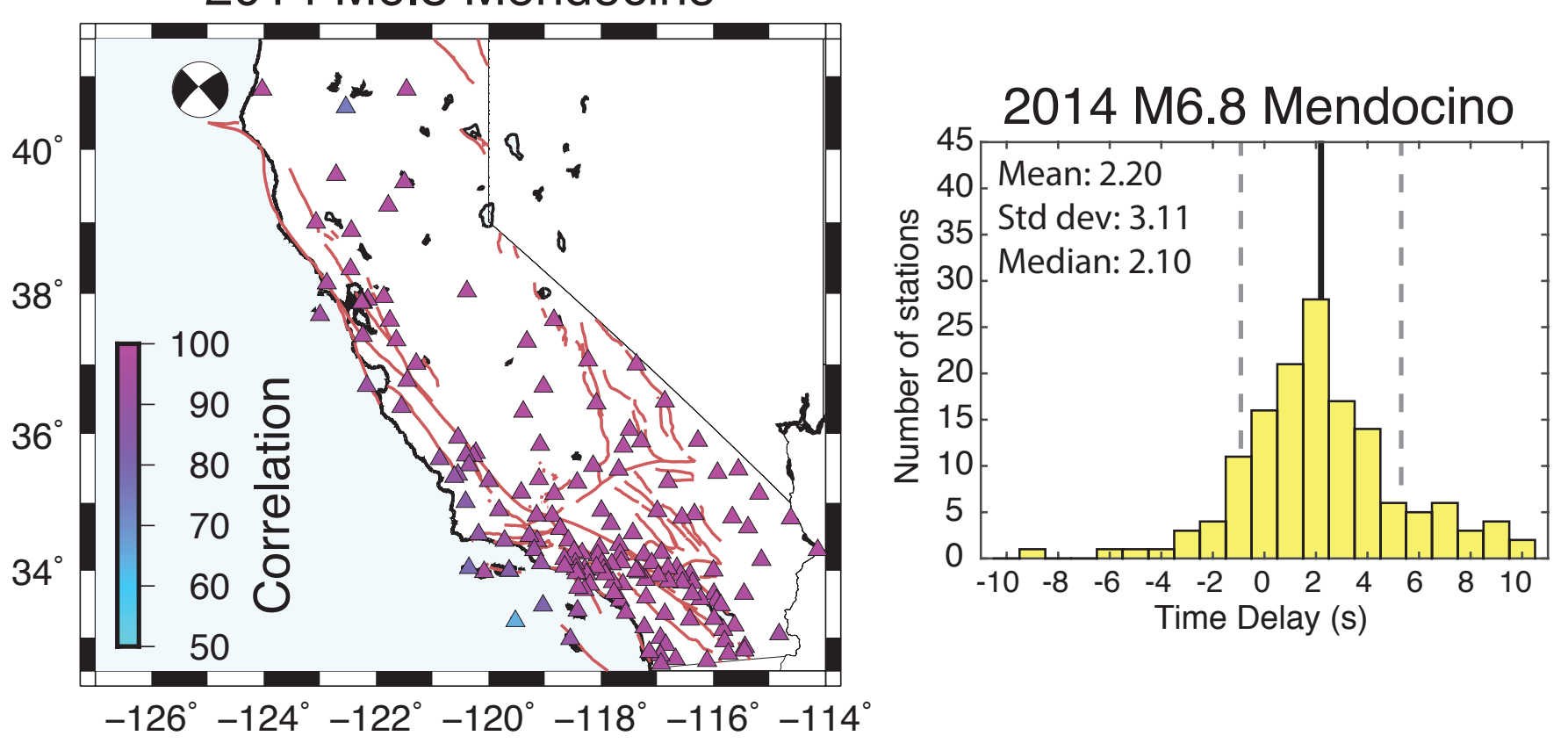
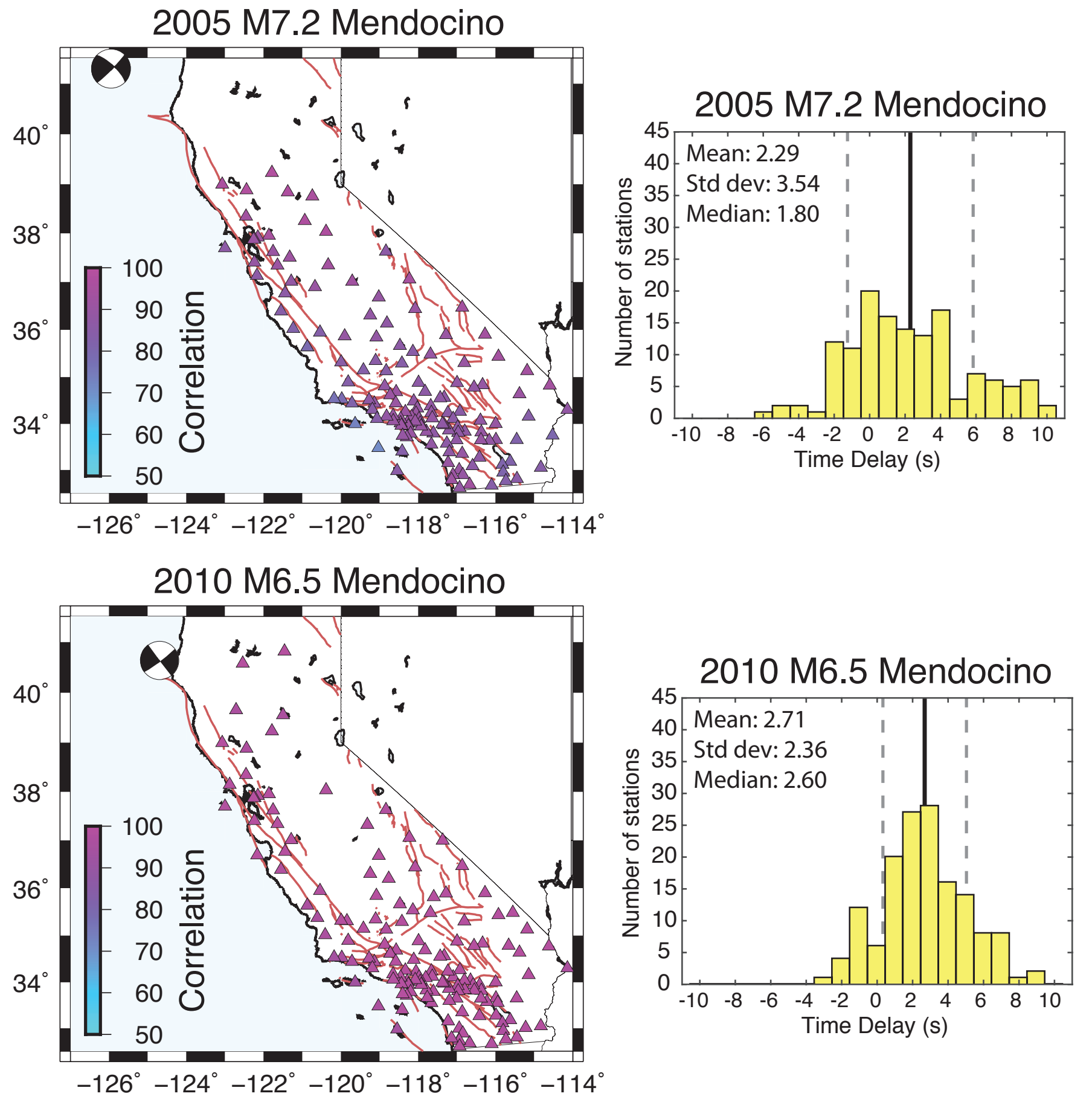
Figure5.pdf M6.8 Mendocino: Coastal Stations

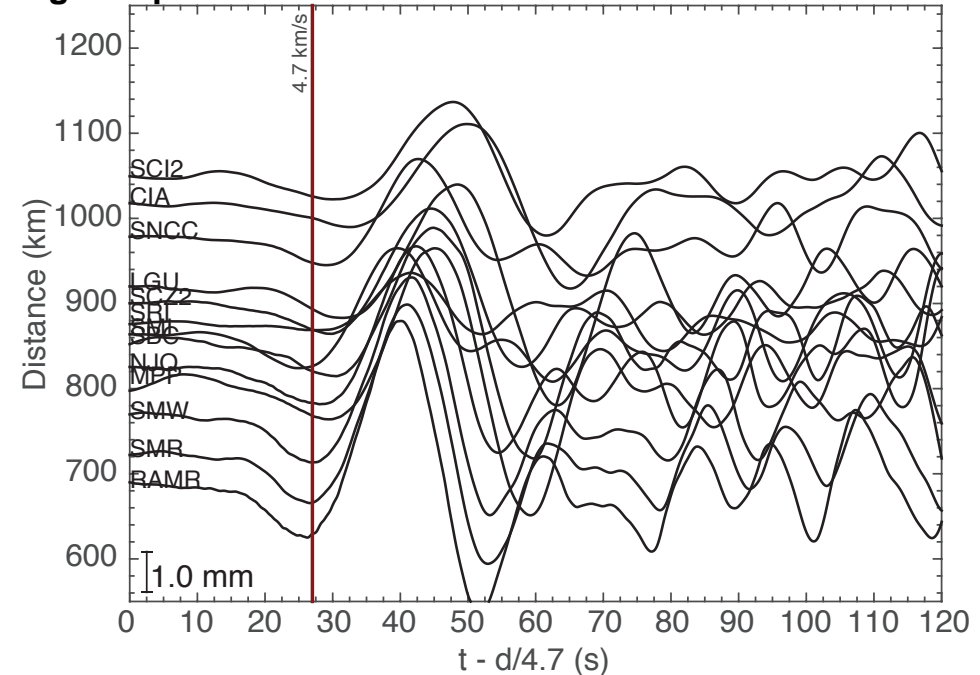

M6.8 Mendocino: Inland Stations

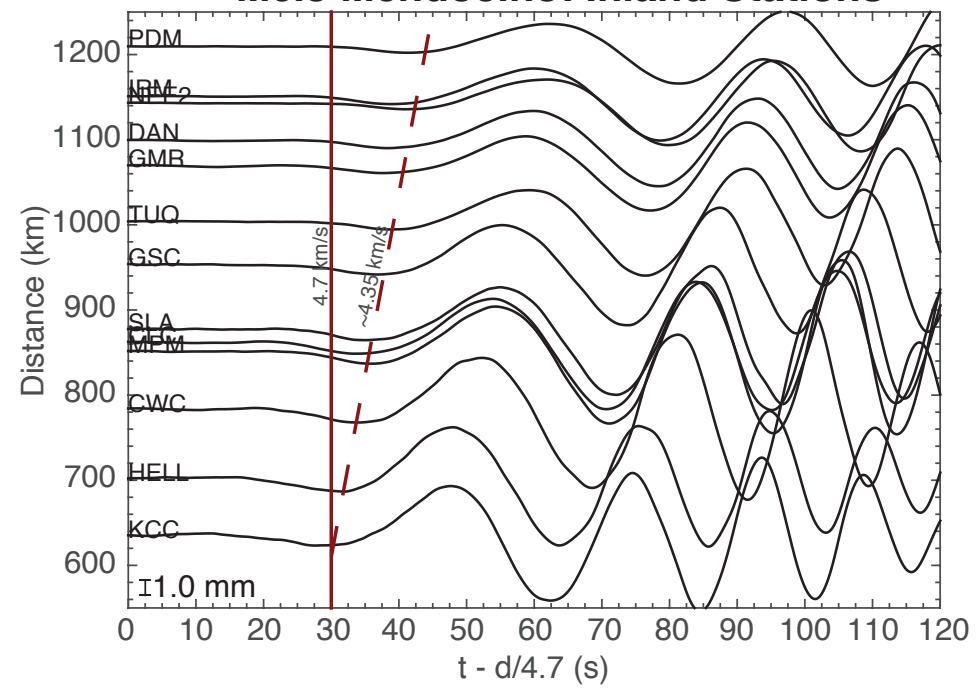

M6.0 Napa: Coastal Stations

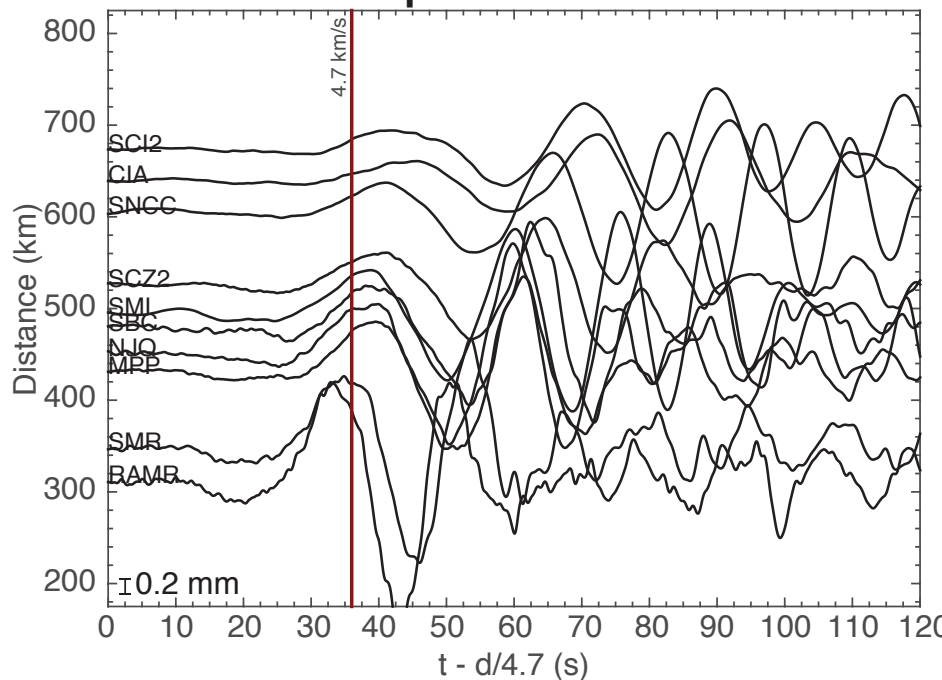

M6.0 Napa: Inland Stations

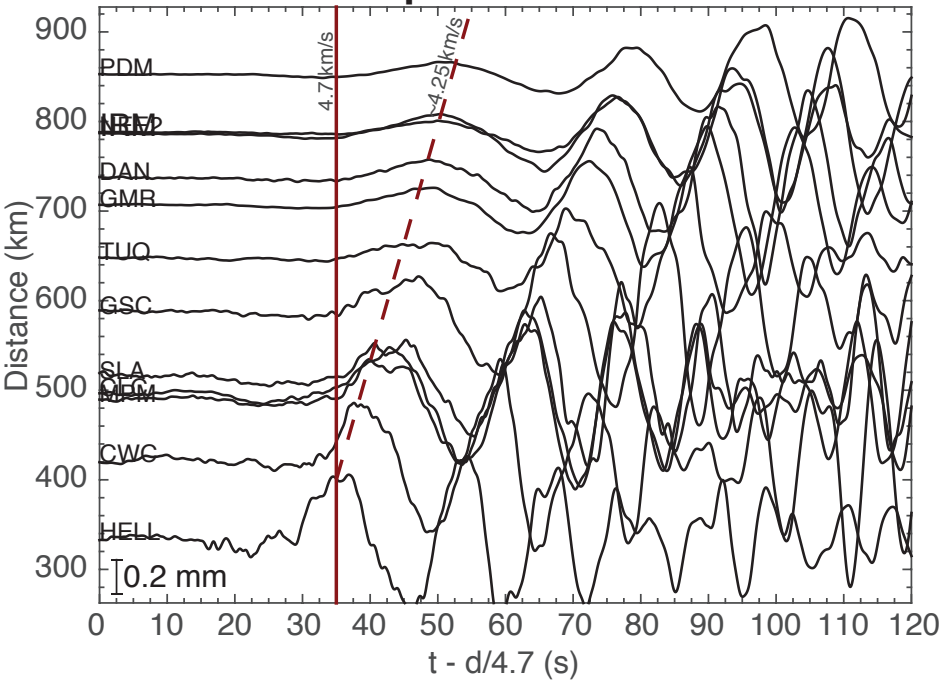



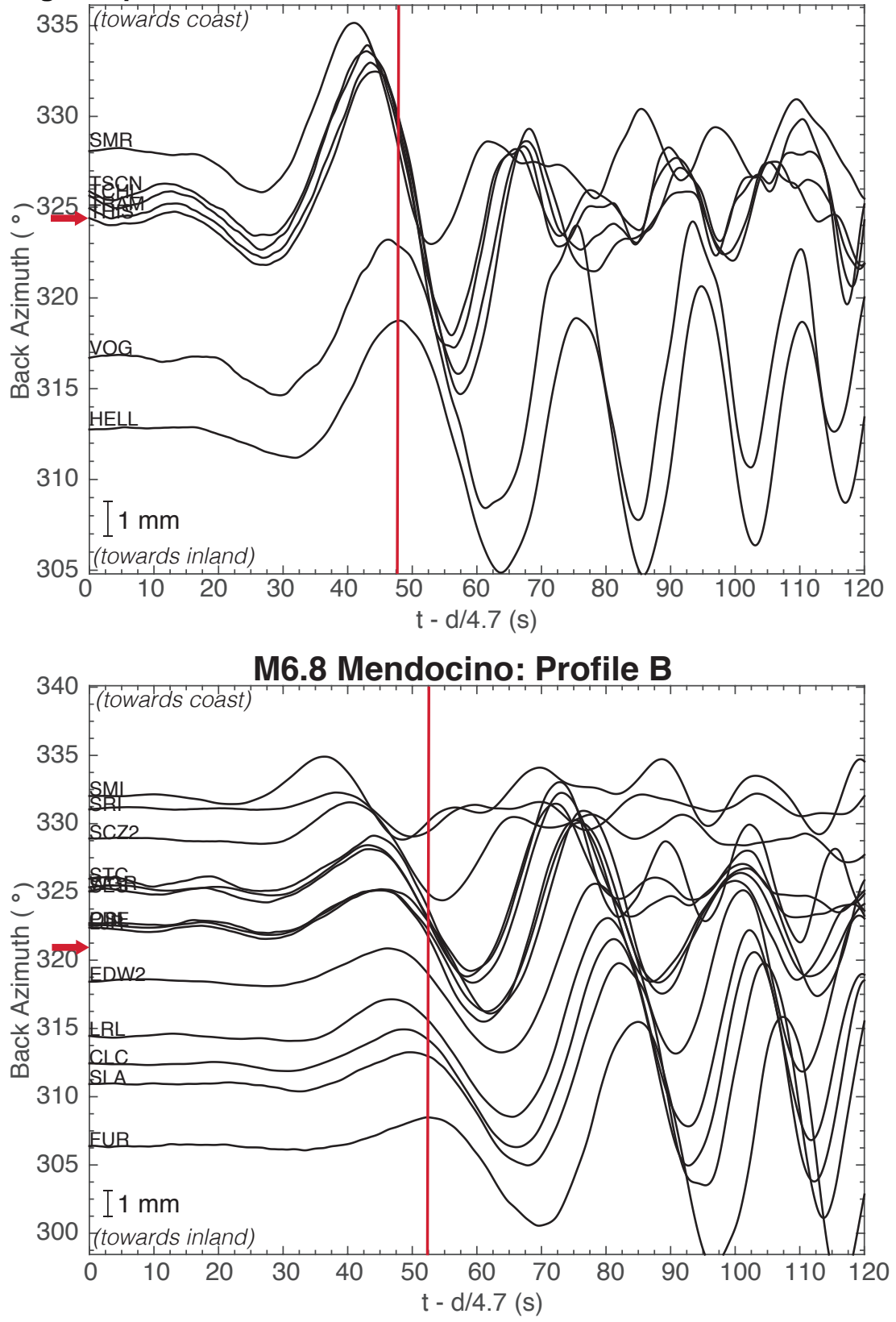

M6.8 Mendocino: Profile C

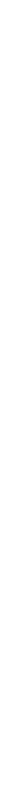




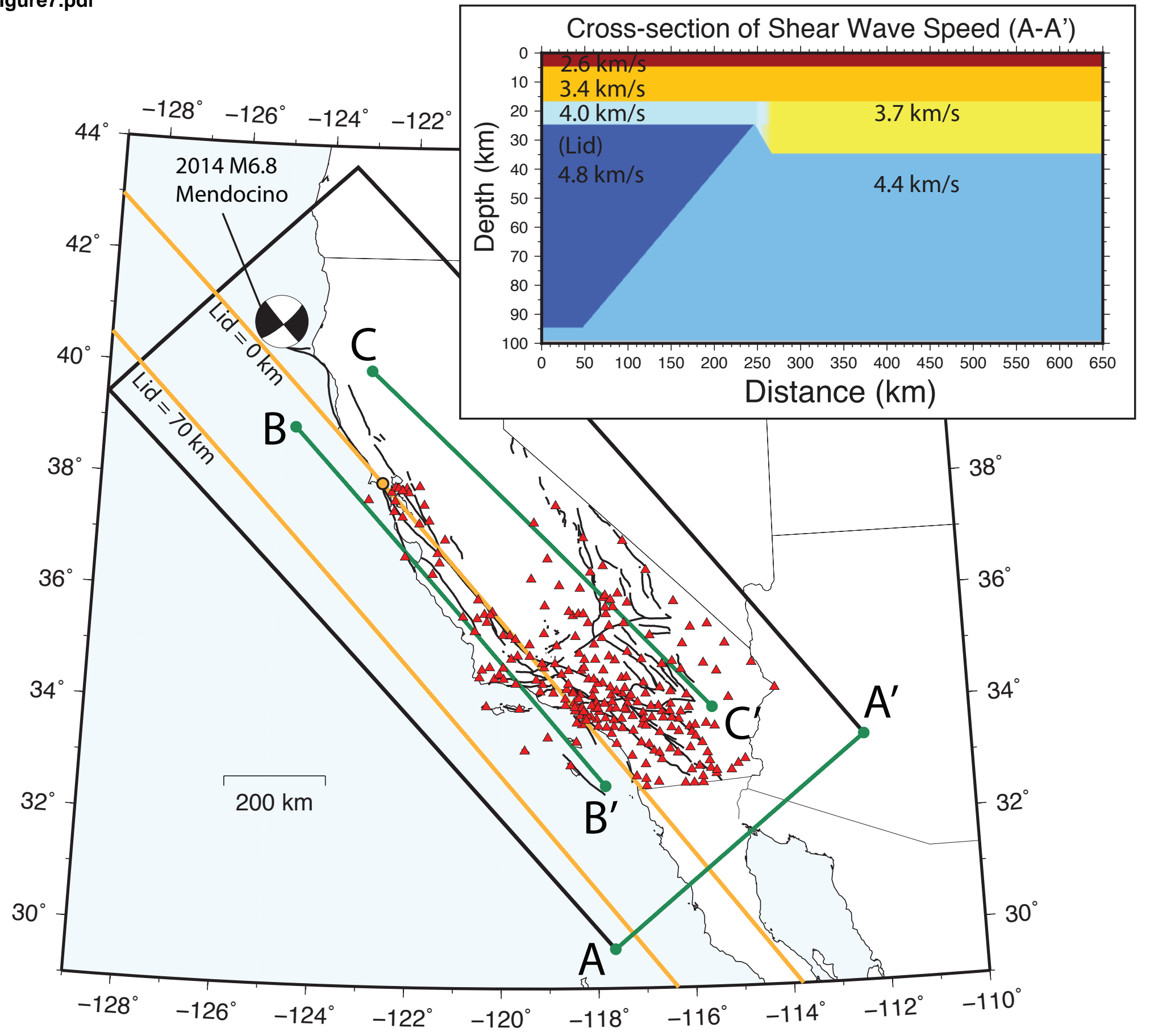


Figure8.pdf
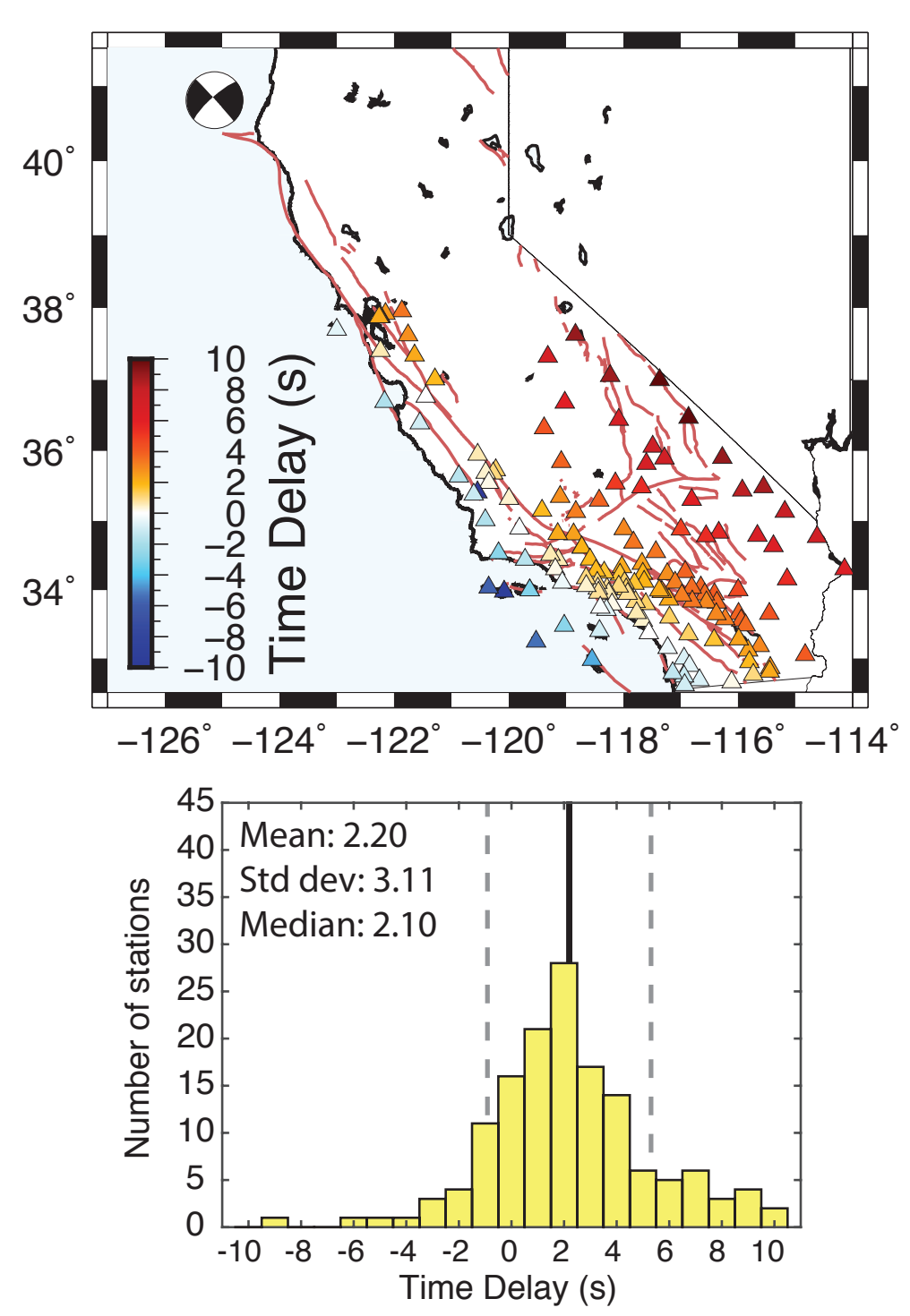

(a)

Data vs. 1D model (b)

Data vs. 3D model (fast lid only)
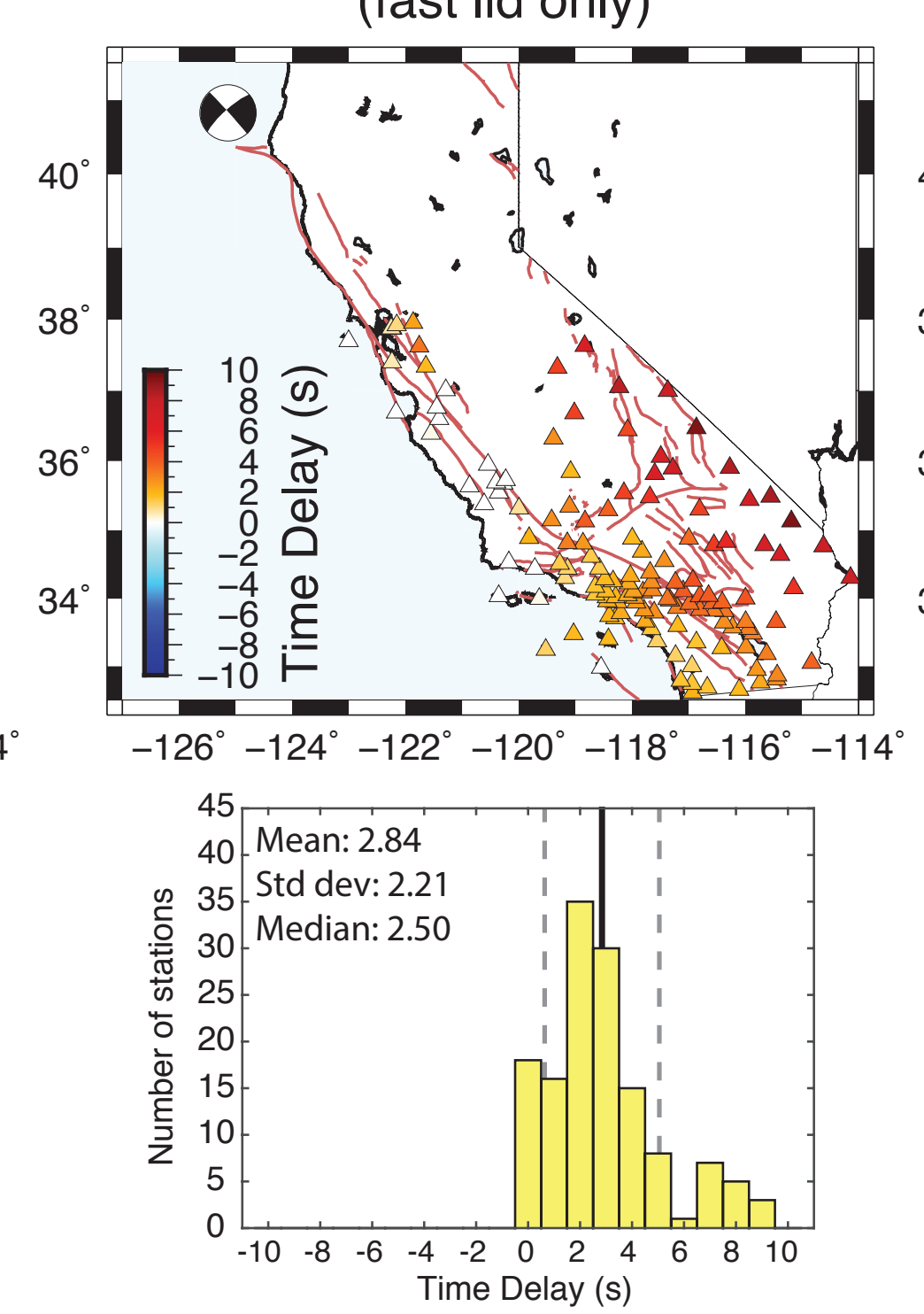

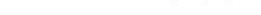
(fast lid + thick, slow crust)
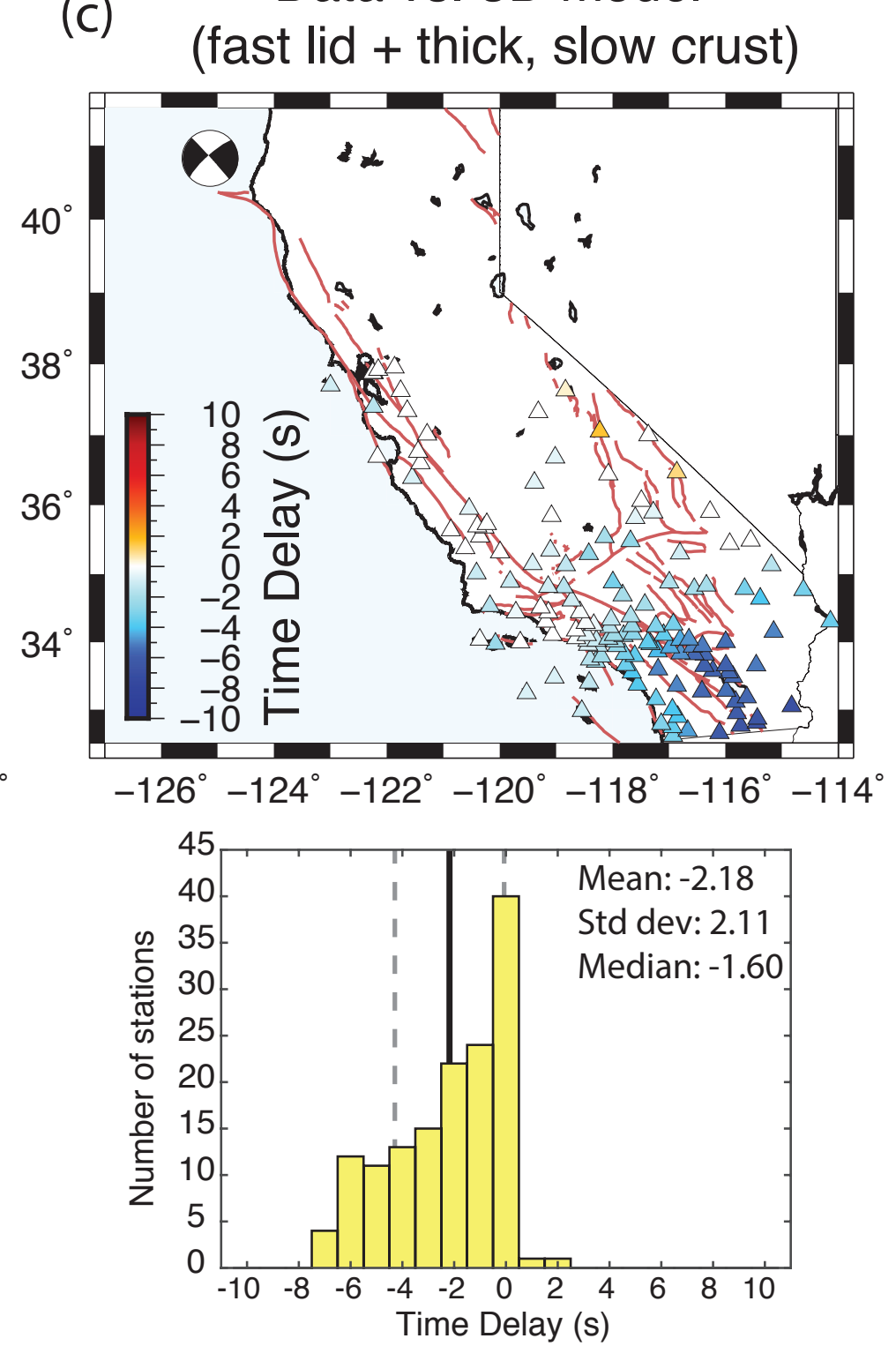

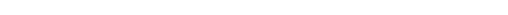


Figure9.pdf (a) Data vs. This Study
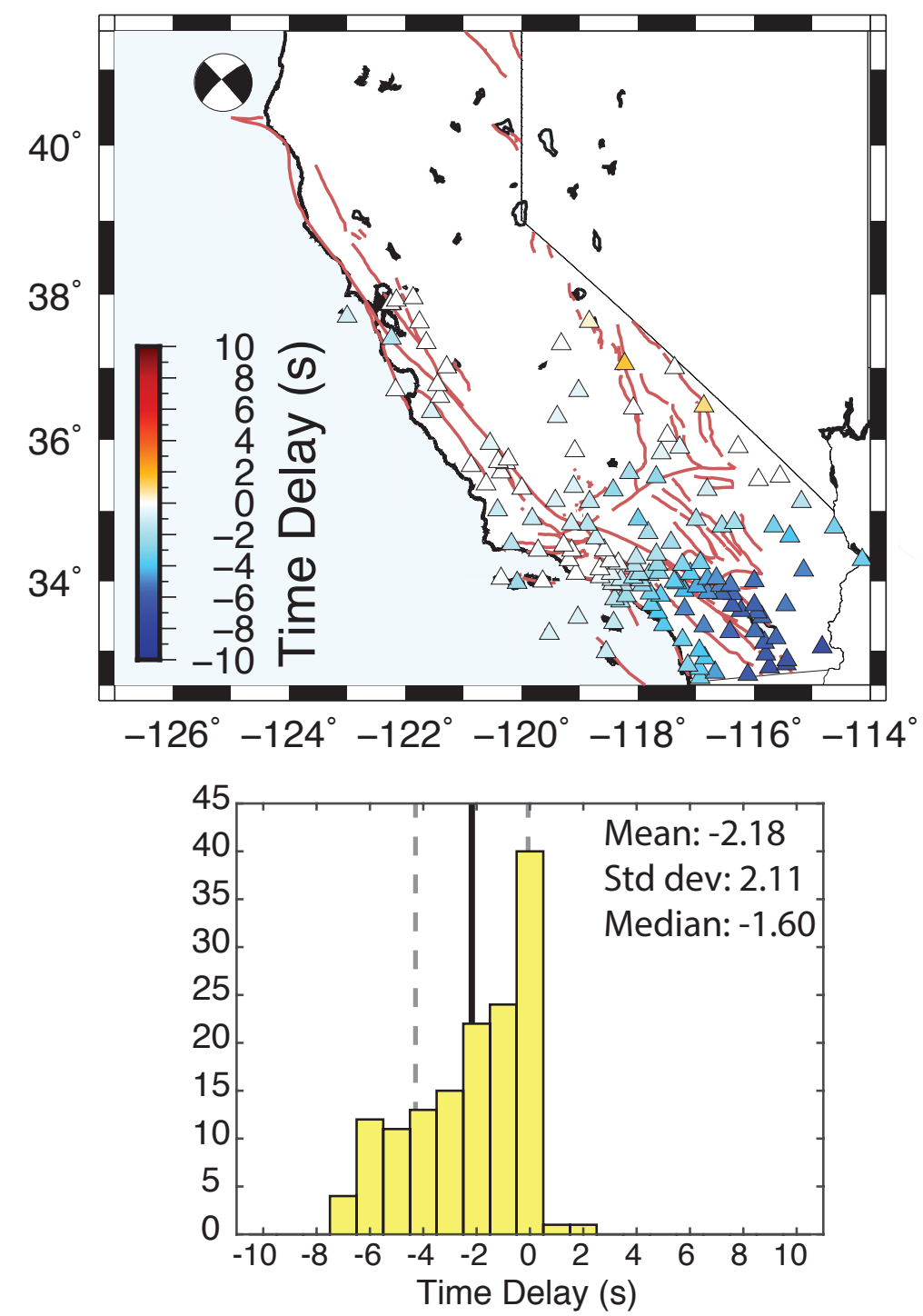

(b) Data vs. USGS+CVM-S4.26 Model
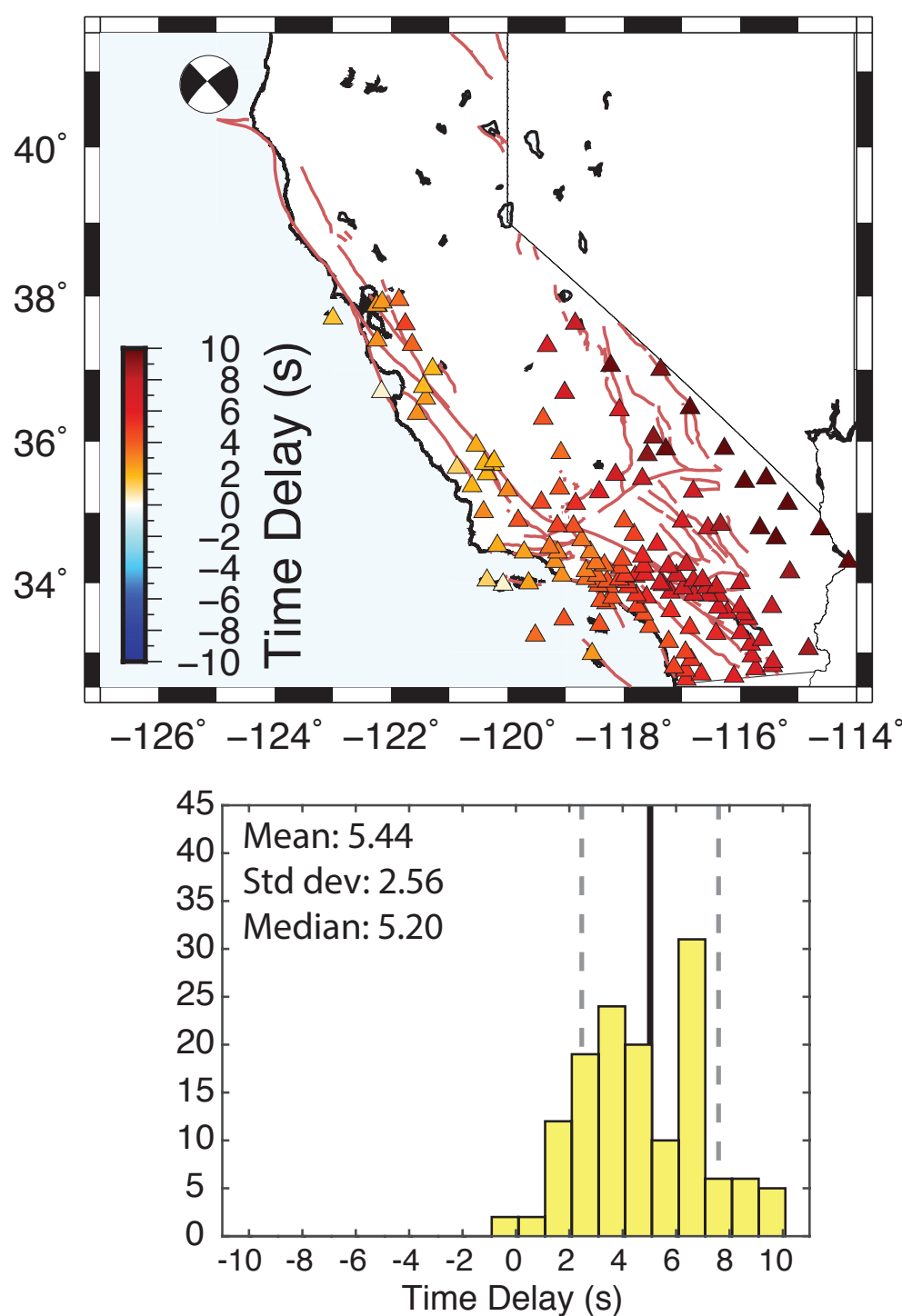

(c) Data vs. USGS+CVM-H Model
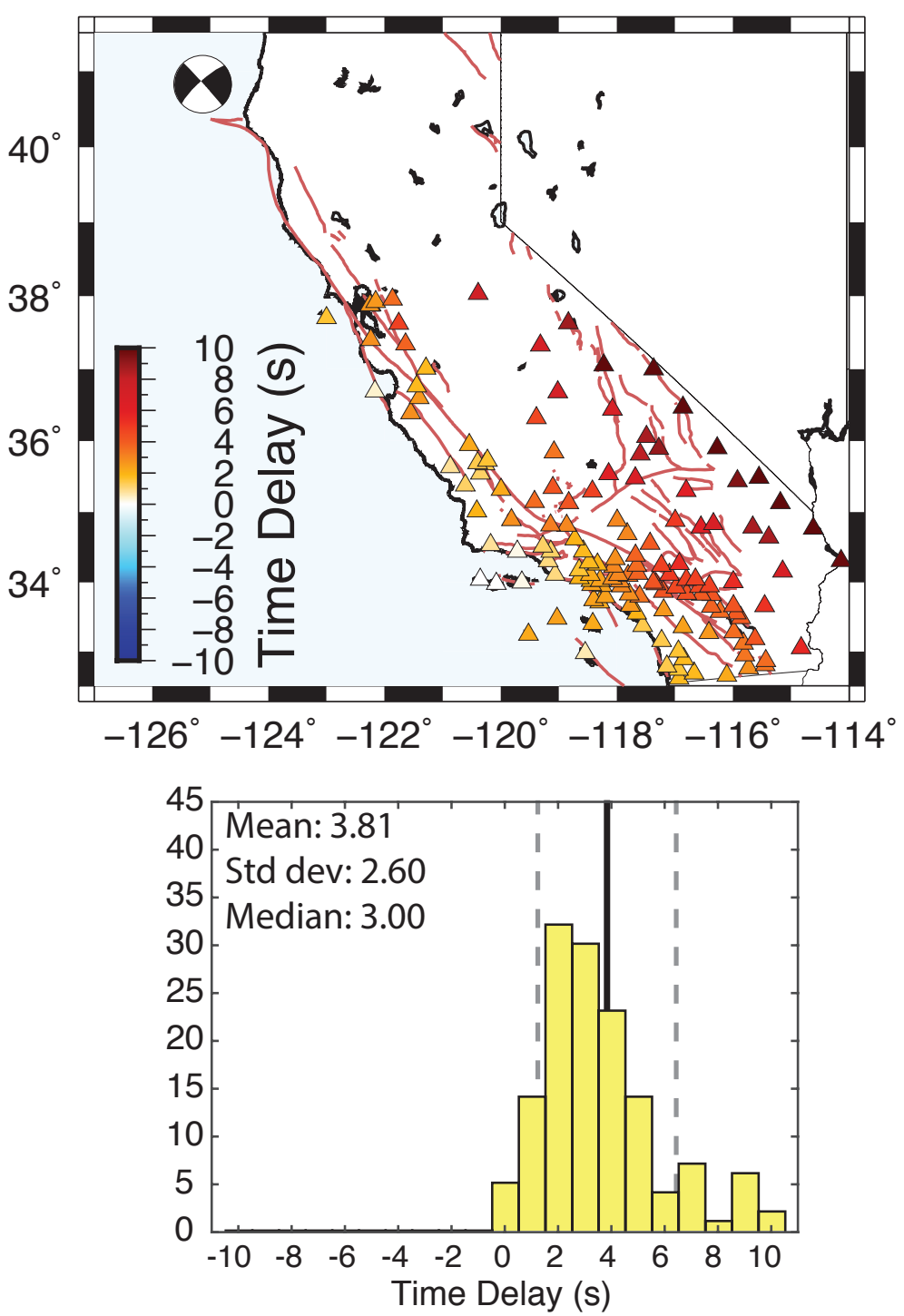
